\title{
Reconciling Environmental Policy with Employment, International Competitiveness and Participation Requirements
}

Thomas Ziesemer

MERIT and Department of Economics, Maastricht University

\begin{abstract}
Politicians understand that a conventional double dividend policy - defined as reduction of greenhouse gas emissions and unemployment through taxation of energy and $\mathrm{CO}_{2}$ emissions and subsidization of wage costs - and the aim of keeping international competitiveness of all sectors intact may be mutually exclusive concepts at least as long as internationally coordinated solutions are not available. It is suggested that a double dividend policy that aims at reducing GHG emissions and unemployment without a direct violation of international competitiveness has to tax energy use and $\mathrm{CO}_{2}$ emissions of households and should use the revenues to subsidize investment in energy or pollution-saving technologies to reduce investment costs of firms. Thereby reduction of energy coefficients is achieved together with lowers costs and prices of goods. This is an increase in competitiveness and employment in an environmentally friendly way and may induce other parts of the world to participate in GHG emission reduction policies or speed up the achievement of an internationally cooperative solution. According to this proposal the principle of causation has to be dropped in part nationally but not internationally. Using these positive incentives, competitiveness of sectors will only be affected through indirect general equilibrium effects.
\end{abstract}

* This paper is a revised version of Chapter 4 of "Energy Technologies, Environmental Policy and Competitiveness", Final Report for JOULE II programme of the European Commission DG XII (F.1) by Paul Diederen, René Kemp, Perry Verberne, Thomas Ziesemer and Adriaan van Zon, MERIT, University of Limburg, May 1995. I would like to thank Paul Diederen, Marcel Janssen, René Kemp, Michael Kohlhaas, Hans van Meijl, Barbara Praetorius, Luc Soete, Perry Verberne and Adriaan van Zon. Seminar participants at the DIW Berlin and the session participants at the 'Jahrestagung des Vereins für Socialpolitik' in Linz/Austria, especially the discussant Peter Michaelis, have been very helpful. Moreover, I would like to thank two anonymous but not unanimous referees for urging for more rigour, brevity and simplification at the same time. Where the paper has been shortened the reader will be referred to the working paper version at "http://www-edocs.unimaas.nl/abs/mer95022.htm". Responsibility for views and opinions expressed is entirely mine and do not necessarily reflect those of the DG XII or the persons mentioned above. Appendices are available at http://meritbbs.unimaas.nl, Research Memoranda 2000. 


\section{Reconciling Environmental Policy with Employment, International Competitiveness and Participation Requirements.}

\section{Introduction}

In the Framework Convention on Climate Change in 1992 in Rio de Janeiro countries agreed on a reduction of $\mathrm{CO}_{2}$ emissions to $85 \%$ of the 1990 level. By 1995 almost no action ${ }^{1}$ has been undertaken as a result because of the Rio agreement. Therefore, at the first conference of parties to the Climate convention held in Berlin 1995 it was agreed to seek legally binding targets. The Kyoto Protocol on Climate Change was expected to achieve this. Did it?

The good news from Kyoto was that other greenhouse gases not considered in previous conventions and an enhancement of the $\mathrm{CO}_{2}$ absorption capacity will be taken into account in future negotiations. This bears some potential to make solutions, if any, less costly (see Michaelis 1999). However, monitoring problems will not become smaller when they are included.

The bad news was that developing countries will not take part and that the US government is not willing to send the Kyoto protocol to the Senate for ratification until developing nations commit to 'substantial participation' which they currently are not willing to do. ${ }^{2}$ Action is postponed again, raising the question what can be done?

As it stands, an international solution with tradable permits does not seem to be feasible politically, mainly because of difficulties in allocating the initial rights and monitoring emissions.

Similarly, an internationally coordinated tax solution suggested by Cooper (1998) is not likely, since other tax and subsidy policies would have to be coordinated by them to avoid an undermining of an agreement (tax carbon, subsidies coal). This requires to surrender countries“ sovereignty, an idea that none will not accept (see Eizenstat 1998).

The EU and its member states reject the idea of national or EU taxation for fear of losing of international competitiveness.

In short, neither internationally traded permits nor internationally coordinated taxes or national tax approaches seem to become a political equilibrium in the near future. The current political equilibrium may, however, be one of positive incentives as used by the Dutch and the US governments subsidizing the adoption of environmentally sound technologies. ${ }^{3}$ However, the corresponding economic equilibrium is not explained conceptually anywhere. In this paper we will explain it using the EC proposal as a starting point. The argument essentially is that the concept is good as long as the other solutions, in particular the internationally coordinated ones are not available. The money invested in this concept so far is insufficient.

The EC proposal for GHG-emission reduction suggests (among other things) the level

${ }^{1}$ The only exception seems to be Switzerland. Britain has shut down its coal industry and Eastern Europe as well as former GDR have closed many industries but these actions where not undertaken because of the Rio agreement. (The Economist, Oct. 11, 1997)

${ }^{2}$ See Jacoby, Prinn and Schmalensee (1998) for a critical evaluation of the Kyoto protocol.

${ }^{3}$ See Vermeend and van der Vaart (1997) on the Dutch concepts and Jacoby, Prinn and Schmalensee (1998) on the US concept. 
of taxation of $\$ 10$ per barrel of oil equivalent with exemptions for energy-intensive industries. Moreover, international competitiveness of firms and unemployment should not be reduced. How taxes should be rebated, however, is an issue left open until now. ${ }^{4}$ Reduction of existing distortionary taxes and subsidies for wage costs have been proposed. Here we argue that subsidies for investment into energy-saving technologies may be a superior way of revenue rebatement that supports the environmental, employment and competitiveness goals. It takes international competitiveness requirements into account right from the beginning instead of making concepts which require exemptions.

We introduce fixed costs and induced energy savings into an economic model with environmental policy. We use a modification of the monopolistic competition model developed by Dixit and Stiglitz (1977), which is now ell-established in the theories of industrial organization, international trade, economic growth and other parts of macroeconomics. The reason is that we prefer a framework suitable for differentiated products over one for homogeneous products; the evidence (see Hall 1988, 1990, Morrison 1989, 1990, 1992 and section 6 of the WP version of this paper) does not contrast the Chamberlinian model of monopolistic competition: At the macro-level and that of highly aggregated sectors profits turn out to be approximately zero. In monopolistic competition models fixed costs limit the number of firms and there is monopolistic price setting. Environmental taxes induce changes of marginal costs and lead to price changes. We allow for many consumption goods. Each variant is assumed to be produced by only one firm which therefore is also the only exporter in the world. The model is extended by Pissaridis' (1990, Chap.1) search unemployment model and with an energy-environment part to analyse the international competitiveness of energy producers and users and the effects on unemployment when environmental policy encourages energy-saving technologies and subsidizes wages. As this paper is concerned with 'what happens in the next ten years after the introduction of an environmental policy', we do not treat technology as an endogenous R\&D variable because the lag from invention to marketing is typically more than ten years in many cases. This means that energy savings for the next ten years will have to be achieved with technologies that are available now. Investment in energy-saving technologies, perhaps of the retrofitting type, constitutes the only form of endogenous technology choice in the model. However, it is easy to imagine that an increase in demand for these technologies increases the incentive for $R \& D$ in this field.

The organisation of the paper is as follows. In section 2 we set up a model which will guide the analysis. In section 3 we show that the impact effects of energy and $\mathrm{C}_{2}$ taxes under the EC proposal and subsidies for investment in energy-saving technologies will be rather limited in spite of the sensitivity of the results with respect to the price elasticities of demand and the level of the tax. In section 4 we examine the decision of the firm, with emphasis on endogenous technology choice reducing energy coefficients through investment in energy-saving technologies, which lowers energy coefficients. In section 5 we argue that a policy that leaves international competitiveness unaffected has to make sure that marginal costs are not increased by taxes. A double dividend or double benefit defined as environmental benefit cum unemployment reduction can be obtained without losses in competitiveness if the revenues from

${ }^{4}$ Pirttilä (1999) has made a start to systematically integrate the issues of policy, compensation, earmarking and environmental taxes. 
energy and $\mathrm{CO}_{2}$ taxes are rebated as subsidies for investment in energy-saving technologies. ${ }^{5}$ Section 6 shows the general equilibrium effects of subsidies on energy-coefficients, unemployment and competitiveness. Section 7 briefly summarizes the argument in a self-contained manner. The reader who is not particularly interested in modelling and technical details can jump to it immediately.

\section{Specification of the model}

The model set up in this section serves several purposes. Firstly, it disciplines the line of thought of this paper. Secondly, it is the basis for some quantifications in later sections. Thirdly, it makes the incentive effects from taxes and subsidies on investment in energy-saving technologies, unemployment and monopolistic inefficiencies explicit.

Assumptions on preferences of households are described by the following utility function

$$
\begin{gathered}
u=\sum_{i=1}^{r} c_{i}^{\alpha}+\sum_{i m} c_{i m}^{\alpha}+\sum_{l} \ln E_{l} \\
i=1, \ldots, r ; i m=r+1, \ldots, r^{*}+r
\end{gathered}
$$

Consumption consists of deliveries from all sectors, $c_{i}$. Some consumer goods, $c_{i m}$, may be imported indirectly. The utility function is of the CES type with respect to the consumer goods and of the ln-type with respect to the environment E. The environmental part of (1) - where $l$ is a country index and the summation over countries reflects global pollution - has marginal utility such that it moves quicker towards infinity if E goes to zero than marginal utility of $c_{i}$ and $c_{i m}$ moves to infinity if $c_{i}$ and $c_{i m}$ go towards zero. In Soete and Ziesemer (1997) this was a necessary assumption to ensure that the environmental tax is positive in the optimum. The positivity problem arises from the inefficiency of monopolistic prices under monopolistic competition. Monopolistic production is lower than optimum production and therefore c.p. should be increased. However, pollution is an argument in favour of reducing output. In the present context it is widely agreed that the environmental tax, whatever its form, should be positive. To make sure that this is a result in general equilibrium and central optimum considerations it was necessary to make the environmental part steeper in marginal utility. Utility function (1) is assumed to reflect the implicit preferences of politicians who favour environmental policy over anti-monopoly policy and material wealth. ${ }^{6}$ Export demand can either be assumed to be derived from a foreign utility function corresponding to (1) with domestic and

${ }^{5}$ In section 7 of the WP, investment dynamics are considered. It is shown that energy and $\mathrm{CO}_{2}$ taxes have a negative impact on investment in the capital stock and on employment whereas subsidies on investment in energy-saving technologies have a positive impact on employment, the environment and international competitiveness. As the model has been changed into a static one this section is dropped here.

${ }^{6}$ This assumption will have no impact on the issues treated in the paper as long as optimal policy is not discussed. 


$$
E x=\sum_{i} x_{i E x}^{\alpha}+\sum_{i} x_{i E x}^{*^{\alpha}} \quad i=1, \ldots, r
$$

imported goods, or, alternatively, from a demand function with constant price elasticities.

Production of domestically produced goods, $x_{i}$, is assumed to have labour requirements

$$
L_{i}=f_{i}+a_{i} x_{i}, i=1, \ldots, r
$$

where f-terms represent fixed costs and a-terms variable costs. a-terms could be endogenized to allow for substitution, which means that they are a function of factor prices. Because of the fixed costs it is advantageous for each firm that enters the market to produce a new variant and not to enter any other firms' market. Therefore each good is produced in one country only. This is the perfect specialization result known from international trade models with differentiated goods.

Technologies of the Energy-Environment complex

Energy is also used as an input by firms in proportion to their output $x_{i}$ :

$$
x_{e i}=a_{e i} x_{i}, i=1, \ldots, r
$$

The indices $i=1, \ldots, r$ are subdivided as follows: non-energy intermediates $i=1, \ldots$, e-1; energy delivering $\mathrm{i}=\mathrm{e}$ and energy-saving intermediates $\mathrm{i}=\mathrm{r}$. For simplicity we consider only one form of energy and one form of retrofitting measures.

Through investment in energy-saving technologies, $\mathrm{i}=\mathrm{r}$, the firms i may reduce energy demand coefficients:

$$
a_{e i}=\underline{a}_{e i}-d_{i} x_{r i}^{\alpha} \equiv g_{i}\left(x_{r i}\right)>0, g_{i}^{\prime}<0, g_{i}^{\prime \prime}>0, \alpha<1
$$

The interpretation of equation (5) is that the coefficients of energy demand, which differ among firms, are reduced by using energy-saving inputs, $i=r$. Households are assumed not to change technologies with respect to energy consumption. But they may reduce energy consumption by investing in retrofitting measures, which are well known to improve living comfort and therefore are part of the utility function. If energy becomes more expansive they invest in thermal insulation measures, which is considered to be a pure substitution of energy. Using the same parameter $\alpha$ in equations (1), (2) and (5) will make the model tractable.

The environmental stock can be thought of as having some natural level $\overline{\mathrm{E}}$ if there is no pollution. Pollution, which diminishes environmental qualities, is proportional to energy production. This is expressed by the pollution coefficient $\mathrm{CO}_{2}$, which is multiplied by the quantity of energy use to express the contribution to pollution (dropping the country index henceforth):

$$
E=\bar{E}-v\left[\left(c+x_{E x}\right)_{e} C O_{2}\right.
$$

$\left(c+x_{E x}\right)_{e}$ is energy production delivered to domestic and foreign consumers. The pollution coefficient $\mathrm{CO}_{2}$ is given at constant values because there are no filters or substitutes available. 
The difference between the natural level $\overline{\mathrm{E}}$ and the vector product results in the environmental stock $\mathrm{E}$ in (6), where $\mathrm{v}$ is a parameter.

The energy tax will be modelled as a specific tax in accordance with the EC proposal. ${ }^{7}$ This means that the firm must pay a tax t to the government for each unit (ton of carbon) of environmental rights to pollute, $\mathrm{CO}_{2}$. Tax payments are described in the following equation:

$$
t(\bar{E}-E)=t \times v \times\left(c+x_{E x}\right)_{e} \times C O_{2}
$$

If the coefficient $\mathrm{CO}_{2}$ is defined as tons of carbon per unit of energy quantity to which it is multiplied, then $t$ is the ECU price for the pollution of a ton of carbon, which is $35 \mathrm{ECU}$ in the EC proposal. Taxing use of energy is an alternative that will be written as an element of the budgets with $\tau$ as the tax rate per GJ of energy type $i$. For simplicity we set $v=1$.

\section{Agents budgets}

Producer $\mathrm{k}$ - where $\mathrm{k}=1, \ldots, \mathrm{r}$ is a certain value of $\mathrm{i}$ - has the following profits from revenues minus costs:

$$
\begin{gathered}
\pi_{k}=p_{k} c_{k}+p_{k E x} x_{k E x}-\left(1-s_{r}\right) p_{r} x_{r k} \\
-\left(p_{e}+t C O_{2}+\tau\right) x_{e k}-\left[w_{k}\left(1-s_{w 1}\right)-s_{w 2}+(\rho+b) p_{k} \gamma / q(\theta)\right] L_{k}=0
\end{gathered}
$$

The first term is deliveries to domestic households, the second is exports; the $s_{r}$-term is an investment subsidy for buying energy-saving technologies; term four, the t-term, is the tax for a ton of carbon emission; the $\tau$-term is a positive or negative tax (subsidy) for energy use, which is negative in case of non-externality types like wind and sun. Energy is measured in gigajoule, GJ. $s_{w 1}$ is an ad valorem subsidy to wages and $s_{w 2}$ is a specific subsidy to wages. The last term consists of ${ }^{8}$ expected real hiring costs $\gamma, \rho$ as a discount rate, $b$ as a breaching or separation rate and $\theta$ as ratio of the rates of vacancies and unemployment, $q(\theta)$ as the probability of the firm to find a worker for a vacancy. Multiplication of real hiring costs by the price of the good in question (for $\mathrm{k} \neq \mathrm{r}$ ), is necessary here because all other expressions are also expressed in nominal terms. All non-energy, energy and energy-saving-technology producers have such a profit function.

\section{Households}

$$
\begin{gathered}
w(1-u) L-\sum_{1}^{r} p_{i} c_{i}-\sum_{r+1}^{r+r^{*}} \tilde{p}_{i m} \tilde{c}_{i m} \\
-t c_{e} C O_{2}-\tau c_{e}+s_{r} p_{r} c_{r}=0
\end{gathered}
$$

${ }^{7}$ The modelling work takes into account several considerations explained extensively in the WP version; see pages 7 and 8 there.

${ }^{8}$ We follow Pissaridis (1990, chap.1) with a slightly different notation. For a condensed introduction see the appendix. 
The first term is wage income. The second and third terms are consumption of domestic and imported goods respectively. The fourth term is the carbon tax payments imposed on households. The fifth term is the energy tax. The sixth term consists of subsidies for energy-saving purchases. ${ }^{9}$ Households differ from firms in that they do not explicitly change energy coefficients but instead are assumed to buy energy-saving technologies instead of energy.

The government budget is assumed to be balanced

$$
\begin{gathered}
t \sum_{k} x_{e k} \mathrm{CO}_{2}+\sum_{k} \tau x_{e k}+t c_{e} \mathrm{CO}_{2}+\tau c_{e} \\
-\sum_{k} s_{r} p_{r} x_{r k}-s_{r} p_{r} c_{r}-\sum_{k}\left[s_{w 1} w+s_{w 2}\right] L_{k}=0
\end{gathered}
$$

Energy is assumed to be imported indirectly; we therefore we do not model import taxes on energy explicitly. The first line of equation (10) contains energy and carbon tax revenues from firms and households. The second line contains subsidies for retrofitting measures - paid to firms and households - and wages.

Current account

$$
\sum_{i m} \tilde{p}_{i m} \tilde{c}_{i m}+m \sum_{1}^{r} x_{e k}-\sum_{i=1}^{r} p_{i}\left(c_{i}-x_{i E x}\right)=
$$

Exports equal imports because debt and interest payments are assumed to be absent. $\mathrm{m}$ is a dummy. If energy is imported it is one, if energy is completely produced domestically it is zero. In different parts of the paper we will make different assumptions on $\mathrm{m}$.

\section{Equilibrium}

Labour market equilibrium requires that labour demand for output production, $\sum_{j} L_{j}$ including energy production and production of energy-saving intermediates, must equal equilibrium employment $(1-\mathrm{u}) \mathrm{L}$, where $\mathrm{u}$ is the rate of unemployment and $\mathrm{L}$ is the labour force. The labour market is therefore characterized by:

$$
\sum_{j} L_{j}-(1-u) L=O
$$

\section{The decision of the household}

The household is assumed to optimize based on expectations and policy announcement information concerning carbon and energy taxes and related subsidies of the household:

${ }^{9}$ Unemployment benefits received and premiums on unemployment insurance drop out in the aggregated budget of households. 


$$
\begin{gathered}
\sum_{i=1}^{r} c_{i}^{\alpha}+\sum_{i m} \tilde{c}_{i m}^{\alpha}+\sum_{l} \ln E_{l}+\lambda\{w(1-u) L \\
\left.-\sum_{1}^{r} p_{i} c_{i}-\sum_{r+1}^{r+r^{*}} \tilde{p}_{i m} \tilde{c}_{i m}-t c_{e} C O_{2}-\tau c_{e}+s_{r} p_{r} c_{r}\right\}
\end{gathered}
$$

Given employment and policy variables $t, \tau$, and $s_{\mathrm{r}}$ the household chooses consumption of all goods including energy and retrofitting measures. Due to the basic decision that the environmental problem is tackled by taxes the household cannot choose the environmental variable $\mathrm{E}$, which therefore will be a pure externality to the household. The first-order conditions are the budget constraint and

$$
\begin{gathered}
c_{i}: \quad \alpha c_{i}^{\alpha-1}-\lambda p_{i}=0, i=1, \ldots, e-1 \\
c_{e}: \quad \alpha c_{e}^{\alpha-1}-\lambda\left(p_{e}+t C O_{2}+\tau\right)=0, \\
c_{r}: \quad \alpha c_{r}^{\alpha-1}-\lambda\left[\left(1-s_{r}\right) p_{r}\right]=0, \\
\tilde{c}_{i m}: \quad \alpha \tilde{c}_{i m}^{\alpha-1}-\lambda \tilde{p}_{i m}=0, \quad i m=r+1, \ldots, r+r^{*}
\end{gathered}
$$

The interpretations are as follows: for non-energy products we have the usual condition that marginal utility equals the price times the value of income. For energy products the tax on $\mathrm{CO}_{2}$ is also a cost element and so is the specific energy tax. For energy-saving products, a subsidy for buying energy-saving products is subtracted from the price.

\section{Impact effects of energy policy on households' energy consumption}

Next we discuss the impact of energy-policy measures on households at prices that have not already adjusted to the new equilibrium, the so called 'impact effect'. The reason for this procedure is that most investigations in the literature present the new equilibrium solution after the introduction of the new policy. However, we do not know how long the adjustment process takes until the new equilibrium is reached and what the path to the new equilibrium will be at least in more complex and realistic models. The impact effect tells what the first reaction of individuals is.

In (13)-(16) the consumer prices (henceforth indexed by an upper index c) are related to producer prices in the following manner:

$$
p_{i}^{c}=p_{i}, \quad \text { with property } \partial p_{i}^{c} / \partial p_{i}=1, \quad i=1, \ldots, e-1
$$




$$
\begin{gathered}
p_{e}^{c}=\left(p_{e}+t C O_{2}+\tau\right), \\
\text { with } \\
\partial p_{e}^{c} / \partial p_{e}=1, \partial p_{e}^{c} / \partial \tau=1, \partial p_{e}^{c} / \partial t=C O_{2}, \\
p_{r}^{c}=\left(1-s_{r}\right) p_{r}, \text { with } \partial p_{r}^{c} / \partial p_{r}=1-s_{r}, \partial p_{r}^{c} / \partial s_{r}=-p_{r},
\end{gathered}
$$

For a sufficiently large number of firms the inverse price elasticity of demand converges towards the last term, $(1-\alpha)$ (see Helpman and Krugman 1985, Chap.6).

The percentage change of consumer demand if the ad valorem subsidy for energy saving purchases is changed can be computed as:

$$
\varepsilon_{c s, r}=\left(\partial c_{r} / c_{r}\right) /\left(\partial s_{r} / s_{r}\right)=-s_{r} \varepsilon_{c p, r} /\left(1-s_{r}\right)
$$

A percentage change in the specific tax on energy can be shown to generate a percentage change in its consumption of:

$$
\left(\delta c_{e} / \delta \tau\right)\left(\tau / c_{e}\right)=\tau \varepsilon_{c p, e} / P_{e}^{c},
$$

An introduction of a carbon tax starting from level zero generates a percentage change of consumption of:

$$
\left(\delta c_{e} / c_{e}\right)=d t \varepsilon_{c p_{e}} C O_{2} / p_{e}^{c},
$$

To compute the effects as expressed in (20)-(22), data on consumer price elasticities $\varepsilon_{c p, i}$ would be necessary on the household level. Unfortunately these are not available for energy-saving products. Long-run price elasticities for residential aggregate energy demand in EU countries are between - 0.23 and -1.40 in Brenton (1994), Kouris (1983) and Mittelstädt (1983). Short-run elasticities are much smaller. Income elasticities are between .49 and 2.43 with most of the estimates being in the neighbourhood of 1. For dis-aggregated fuels we have estimates by Maddala et al. (1997), Brenton (1994) and from Deaton (1975, based on British data). In Maddala et al. (1997) they are between -.83 and 1.328 in the short run for electricity and .048 to .037 for gas. In Deaton (1975) we find income elasticities between -4 for coal and +3.7 for electricity and price elasticities between +2 for coal and -2.9 for gas. In Maddala et al. (1997) short-run price elasticities range from -.158 to -.214 for electricity and -.092 to -.177 for gas. ${ }^{10}$ In Brenton (1994) we find compensated own price elasticities between -.65 for electricity in Denmark and -.87 in Spain and expenditure elasticities of about unity for all countries and fuels. ${ }^{11}$

\footnotetext{
${ }^{10}$ These authors present many more results for alternative econometric methods.

${ }^{11}$ The difference between the results of Deaton and Brenton seems to be rather extreme and supposedly stems from the different methods as discussed in footnote 3 in Brenton (1994) and more broadly in Deaton (1975). Brenton, Kouris, Mittelstädt and Deaton all provide a
} 
Long-run price elasticities for gas and electricity are between -0.2 and -4.6 according to a summary of old literature in Li and Maddala (1999); for the short run the corresponding values are between -0.05 and -0.9 .

We can only compute the effects modelled above for different values of the elasticities $\varepsilon_{c p, i}$. We use alternative values of uncompensated price elasticities $\varepsilon_{c p, i}=-1.1,-2,-4,-10$. Sectoral elasticities on the highly aggregated level are lower because inter-fuel substitution vanishes in the aggregation. But even on the level of single fuels the data reflect aggregates across firms and therefore exclude the effects on price elasticities of inter-firm competition. Remember that for monopoly prices to exist price elasticities have to be smaller than minus one. Otherwise monopoly profits could be infinitely high, a situation that is hardly realistic.

For a scenario on (20) we use an ad valorem investment subsidy of 10\%, 25\% and 50\% respectively. The results for (20) are summarized in Table 1.

Table 1

\begin{tabular}{|c|c|c|c|}
\hline$\varepsilon_{c p, i}^{s_{i}}$ & $10 \%$ & $25 \%$ & $50 \%$ \\
\hline-1.1 & .12 & .36 & 1.1 \\
\hline-2 & .22 & .66 & 2 \\
\hline-4 & .44 & 1.33 & 4 \\
\hline-10 & 1.1 & 3.33 & 10 \\
\hline
\end{tabular}

The interpretation of results in Table 1 are as follows. Increasing the subsidy for energy saving purchases by $1 \%$,e.g., from $25 \%$ to $25,25 \%$ increases the demand for energy saving products by $\mathrm{x} \%$, where $\mathrm{x}$ is the number in Table 1 . If, for example, the subsidy is $50 \%$, a change to $50,50 \%$ increases the demand for energy-saving products by a percentage equal to the price elasticity (see last column). With low price elasticity -1.1 and only $10 \%$ subsidy a change to a $10,1 \%$ subsidy increases the demand by $.12 \%=1,2 \%$. The higher the level of the subsidy and the elasticity assumed, the stronger the effect of a $1 \%$ increase of that subsidy. The reason is that for each ECU a $1 \%$ increase in the ad valorem subsidy implies that the money value of the 10,25 , and $50 \%$ subsidy is 1, 2.5 or 5 ECU cent respectively - which means that a larger amount of money is involved. However, the range for $\varepsilon_{c s, i}$ is rather broad: it goes from .1 to 10. Sectoral price elasticities and those for household panels (see SEO 1992) are even lower than those used here for households. In that case an elasticity of unity will only be reached for a subsidy higher than $50 \%$.

Next we look at the effect of a carbon tax on households' demand for energy. We have price data (see Europäische Gemeinschaften 1994) and carbon emission coefficients (see IPCC Draft) for natural gas and heating gas oil. The EC average price for natural gas is 13 ECU per gigajoule (GJ). This is also the price for Germany. The emission coefficient is .02 ton carbon per

sophisticated discussion with respect to the reliability of these estimates. 
GJ (ton C/GJ). For heating gas oil (residential fuel oil) the average price is 12 ECU/GJ. This is also the price for the Netherlands, Spain and France). The emission coefficient for heating gas oil is .015 ton C/GJ. EC average prices for electricity are $23 \mathrm{ECU} / \mathrm{GJ}$, which is also the price for Spain and Belgium, but emission coefficients are not available. With a carbon tax of 35 ECU per tonC as suggested by the EC proposal mentioned above, these (all taxes included) prices become $(13+35 \times 0.015) \mathrm{ECU}=13,7 \mathrm{ECU}$ and $(12+35 \times 0.015) \mathrm{ECU}=12.525 \mathrm{ECU}$. The increase in the price is therefore $7 \mathrm{ECU}$ per GJ natural gas and $.525 \mathrm{ECU}$ per GJ heating gas oil which is a price increase of roughly $5 \%$ induced by the carbon tax alone. In Table 2 we summarize the percentage changes in consumption, $\mathrm{dc} / \mathrm{c}=\mathrm{dtCO} \mathrm{Ci}_{2 \mathrm{i}} / \mathrm{p}^{\mathrm{c}}$, of natural gas and heating gas oil from a carbon tax, dt, of ECU 20, 35, 50 and 100 for the same elasticity as in the above scenarios derived from equation (22) based on price effects alone. Income effects and cross-price elasticities from taxes on other fuels will be discussed separately below.

Table 2

Impact effects of a carbon tax on private households change in consumption, $\mathrm{dc}_{\mathrm{e}} / \mathrm{c}_{\mathrm{e}}$, of natural gas and heating gas oil

\begin{tabular}{lcccr}
\multicolumn{5}{c}{ Natural gas } \\
carbon tax (ECU/ ton) & 20 & 35 & 50 & 100 \\
$\varepsilon_{c p, e}$ & & & & \\
-1.1 & -.034, & -.06 & -.08 & -.17 \\
-2 & -.06, & -.108 & -.154 & -.31 \\
-4 & -.12, & -.216 & -.308 & -.62 \\
-10 & $-3 .$, & -.54 & -.77 & -1.55
\end{tabular}

\section{Heating gas oil}

carbon tax $(\mathrm{ECU} /$ ton $)$

20

35

50

100

$\varepsilon_{c p, e}$

$-1.1$

$-.028$

$\underline{-.048}$

$-.069$

$-2$

-.05 ,

$-.0875$

$-.125$

$-.25$

$-4$

-.1 .

$-.175$

$-.25$

$-10$

-.25 ,

$-.438$

$-.625$

In Brenton (1994), Hermes (1993) and the summary of Li and Maddala (1999) and Maddala et al. (1997) (compensated own price) elasticities for household aggregates in the short run are below unity. Elasticities in SEO (1992) for gas are also below one percent. The use of lower values will make the conclusion drawn below even stronger.

A carbon tax of $35 \mathrm{ECU}$, inducing a $5 \%$ price increase, will decrease demand for natural 
gas and heating gas oil by $6 \%$ and $4,8 \%$ (underlined number in Table 2 ) respectively under a price elasticity of -1.1 if the effect on substitutes - some of which have to bear a carbon tax as well is ignored. Price elasticities reported in the literature are at the lower end of the above scenario.

Table 3

Impact effects of an energy tax on private households percentage change in consumption, $\mathrm{dc}_{\mathrm{e}} / \mathrm{c}_{\mathrm{e}}$, of natural gas, heating gas oil and electricity

\section{Natural gas}

energy tax

.3

.7

1.0

1.4

(ECU per GJ)

$\varepsilon_{c p, e}$

$-1.1$

-.025 ,

$-.06$

$-.08$

$-.118$

$-2$

$-.048$

$-.1$

$-.15$

$-.22$

$-4$

-.09 ,

$-.21$

$-.3$

$-.43$

$-10$

$-.23$

$-.54$

$-.77$

Heating gas oil

energy tax

.3

.7

1.0

1.4

(ECU per GJ)

$\varepsilon_{c p, e}$

$-1.1$

-.028 ,

$-.06$

$-.06$

$-.13$

$-2$

-.05 ,

$-.117$

$-.17$

$-.23$

$-4$

-.1 ,

$-.23$

$-.33$

$-10$

-.25 ,

$-.58$

$-.83$

$-1.16$

\section{Electricity}

energy tax

.3

.7

1.0

1.4

(ECU per GJ)

$\varepsilon_{c p, e}$

$-1.1$

-.014 ,

$-.03$

$-.05$

$-.06$

$-2$

$-.026$

$-.06$

$-.09$

$-.12$

$-4$

$-.052$

$-.12$

$-.17$

$-.24$

$-10$

$-.13$

$-.3$

$-.43$

Impact effects of an energy tax on energy consumption are considered in Table 3 . Under the EC proposal there will be a change of the energy tax, $d \tau$, of .7 ECU per Gigajoule. Table 3 
contains scenarios for the change in consumption $\mathrm{dc}_{\mathrm{e}} / \mathrm{c}_{\mathrm{e}}=\varepsilon_{c p, e} d \tau / p_{e}{ }^{c}$ of formula (21) with energy tax change, $d \tau$ varying from .3 to 1.4 , i.e from less than half to twice the amount contained in the EC proposal. Gigajoule prices $p_{i}{ }^{c}$ corresponding to that formula are $13 \mathrm{ECU}$ for natural gas, 12 ECU for heating gas oil and 23 ECU for electricity, all of which are EC average prices taken from Europaeische Gemeinschaft (1994).

Under the EC proposal and the lowest (absolute) price elasticity, 1.1, the percentage change of GJ consumption of natural gas, heating gas oil and electricity will be $6 \%, 6 \%$ and $3 \%$ respectively if income and cross-price effects from taxes on other fuels are ignored. For electricity this value has been obtained under the assumption that there is an energy tax only at the level of households. These values will be different if coal and other fuels are used and taxed on the input level. In this case there can be a carbon and an energy tax on inputs for producing electricity.

The upper bound of an impact effect of an introduction of the EC proposal - still postponing discussion of income and cross-price effects generated by taxes on other fuels - can be obtained from adding up the percentage values of the 35-column of Table 2 and the .7 column of Table 3. For alternative elasticity values of demand with respect to price this yields the results of Table 4.

Table 4

Impact effect of an introduction of the EC proposal on energy consumption

$\begin{array}{lrrrr}\varepsilon_{c p, i} & -1.1 & -2 & -4 & -10 \\ \mathrm{dc} / \mathrm{c}^{1} & -.12 & -.21 & -.43 & -1.1 \\ \mathrm{dc} / \mathrm{c}^{2} & -.11 & -.21 & -.41 & -.926\end{array}$

1 for natural gas and 2 for heating gas oil.

Deaton (1975) finds an elasticity of -2.9 for gas demand in Britain. Applying that value here the impact effect would be roughly a 30\% demand reduction as the starting point for analysing the price effect of a $10 \%$ price increase from carbon and energy taxes according to Table 4 . To do so, the following modifications are necessary:

i) These effects have been calculated using the EU average price of $13 \mathrm{ECU}$ for natural gas and $12 \mathrm{ECU}$ for heating gas oil when doing the division in the formula presented above. However, households pay higher prices in almost all countries. Dividing by higher prices reduces the effects of the above computations. In some cases the effects are reduced by more than one half.

ii) In Mittelstädt (1983) short-run elasticities of prices are about $1 / 4$ of the long-run elasticities reducing this number from $30 \%$ to a $7.25 \%$ reduction of demand for natural gas and heating gas oil.

iii) Other energy forms also have to bear these taxes and therefore cross-price elasticities will soften this effect. Therefore these are upper limits for single energy forms.

iv) All results from Tables 2-4 are extremely sensitive to the values of the tax rates, the price elasticities and the price paid.

The income effect alone will be small: If a household spends as much as $1 / 3$ of income on housing and $20 \%$ of that on energy then the energy share of total household expenditure is $6 \%$. 
A price increase of $10 \%$ decreases his real income by $.6 \%$. With an income elasticity of unity the income effect will decrease demand by (-.6\%). Even if the income elasticity is at the highest level that can be found, 2.4 , the demand decrease will be only $1.44 \%$.

If the mixture of energy and carbon taxes keeps the structure of demand approximately constant and the price and income elasticities are at the upper value of the estimated ranges -1.4 and 2.4 respectively - the price increase of $10 \%$ and the income decrease of .6\% decrease energy demand by $15.5 \%$. This is the uppermost level of possible demand reductions. Most estimates in Kouris (1983), Mittelstädt (1983), Brenton (1994), Li and Maddala (1999) and Maddala et al. (1997) are half that size. This is leading to a long-run effect of a $7.7 \%$ energy demand reduction from households from the EC proposal values reached at the end of the "phasing in". With short-run price elasticities of -.2 and an income elasticity of 1 (taken from the same literature and applied to the price increase of $10 \%$ and the income decrease of .6\%) the reduction in energy demand will be $2 \%+.6 \%=2.6 \%$ in the short run. This is much less than the reduction in energy demand during recessions. Clearly, for less $\mathrm{CO}_{2}$ intensive energy forms than natural gas and heating gas oil the price increase is lower. For more $\mathrm{CO}_{2}$ intensive energy forms the price increase is higher, but this is mainly coal for which there are special rules of the game anyway. All in all, given the necessity to protect the environment, the reduction of competitiveness of energy, compared to other products, seems to be at a minimum.

\section{The decision of monopolistically competitive producers}

Producers choose: i) supply quantities $x_{k} \equiv c_{k}+x_{k E x}$; ii) purchases of energy and energy-saving intermediates where energy-saving purchases reduce the energy coefficients according to (5); iii) labour demand $L_{k}$ from (3). The problem of the firm $\mathrm{k}$ then is to maximize profits as defined in equation (8) subject to equations (3), and domestic and foreign demand functions. Inserting (3), (4) and (5) into the profit function (8), yields the unconstrained profit function to be maximized:

$$
\begin{aligned}
\pi_{k}= & p_{k} c_{k}+p_{k E x} x_{k E x}+\left(s_{r}-1\right) p_{r} x_{r k}-\left(p_{e}+\tau+t C O_{2}\right) g_{k}\left(x_{r k}\right)\left(c_{k}+x_{k E x}\right) \\
& -\left[w_{k}\left(1-s_{w 1}\right)-s_{w 2}+(\rho+b) p_{k} \gamma / q(\theta)\right]\left[f_{k}+a_{k}\left(c_{k}+x_{k E x}\right)\right]
\end{aligned}
$$

The first-order conditions for firms are (3), (4), (5) and (with $\mathrm{k}=1, \ldots, \mathrm{e}-1, \mathrm{r}$, i.e. for non-energy firms)

$$
\begin{gathered}
\delta \pi_{k} / \delta x_{k}=p^{\prime} x_{k}+p_{k}-\left(p_{e}+t C O_{2}+\tau\right) g_{k}\left(x_{r k}\right)- \\
\left.w_{k}\left(1-s_{w 1}\right)-s_{w 2}+(\rho+b) p_{k} \gamma / q(\theta)\right] a_{k}=0, k=1, \ldots, e-1, \\
\partial \pi_{k} / \partial x_{r k}=\left(s_{r}-1\right) p_{r}-\left(p_{e}+t C O_{2}+\tau\right) g_{k}^{\prime}\left(x_{r k}\right) x_{k}=0, \\
k=1, \ldots, e-1, r
\end{gathered}
$$

The interpretation of the first-order conditions is as follows. Equation (23) states that marginal revenue equals marginal costs. $\mathrm{CO}_{2}$ and energy taxes increase marginal costs and wage subsidies 
decrease marginal costs. ${ }^{12}$ (24) states that the value of subsidies plus the value of the reduction of the energy coefficients equal the price paid for the energy-saving technologies. It follows from (24) that all firms generate the same product $g_{k}$ ' $x_{k}$ through their technology choice. Due to the specification of (5), equation (24) generates a constant inverse price elasticity of $\mathrm{x}_{\mathrm{rk}}$, which is the same as for all other goods. Energy is assumed to be imported in this section and the rest of the paper.

\section{Policies when competitiveness is guaranteed}

The implications of energy and carbon taxes on firms' and households' behaviour can now be considered. Marginal revenue equals marginal cost, leading to a price

$$
\begin{gathered}
P_{k}=M C /\left(p^{\prime} x_{k} / p_{k}+1\right) \text { with } M C \equiv \\
\left(p_{e}+t C O_{2}+\tau\right) a_{e k}+\left[w_{k}\left(1-s_{w 1}\right)-s_{w 2}+(\rho+b) p_{k} \gamma / q(\theta)\right] a_{k}
\end{gathered}
$$

The impact of a change of carbon and energy taxes and wage subsidies on marginal cost is

$$
\begin{gathered}
d M C=\left(p_{e}+t C O_{2}+\tau\right) d a_{e k}+ \\
d t a_{e k} C O_{2}+d \tau a_{e k}+\left[w_{k}\left(-d s_{w 1}\right)-d s_{w 2}\right] a_{k}
\end{gathered}
$$

Energy and carbon taxes on the one hand provide an incentive to reduce energy coefficients and therefore decrease marginal costs. On the other hand, for given energy coefficients, they increase marginal costs whereas wage subsidies decrease marginal costs. Wage subsidies are therefore an instrument to compensate firms in a way that potentially leaves their marginal cost position unaffected by carbon and energy taxes. Subsidies on energy-saving measures don't have this positive effect because they decrease fixed costs directly and energy input coefficients and marginal costs indirectly. However, if marginal costs are kept constant to ensure international competitiveness and therefore prices, output and labour demand are not decreased by carbon and energy taxes (see Figure 1). The only effect then is to reduce energy input coefficients and pollution. This latter effect, of course, is absent under an exemption from a carbon tax - in the model above and also empirically (see Denis and Koopman 1995) - unless there are subsidies for energy-saving measures. ${ }^{13}$

A way to reduce pollution further if wage subsidies keep marginal costs non-increasing is to pay energy-saving subsidies as well. All this raises the crucial question whether their is enough money from energy and carbon taxes to keep marginal costs constant except for the effect of paying subsidies for energy-saving investments. This question can be analysed as follows.

All policy measures that change marginal cost in this model are assumed to start at value

\footnotetext{
${ }^{12}$ Although the price also appears in the valuation of the hiring costs, the firm is assumed not to take into account that it might have any impact on this valuation. That price is also the price of all other goods except for good $r$.

${ }^{13}$ Dynamic investment effects are discussed in section 7 of the working paper version.
} 
zero, which implies $d t=t, d \tau_{i}=\tau, d s_{w 1}=s_{w 1}, d s_{w 2}=s_{W 2}$. Inserting this into dMC $=0$ yields the condition for constant marginal costs or an unchanged competitive position of a firm:

$$
\begin{gathered}
d a_{e k} p_{e}+t a_{e k} \mathrm{CO}_{2}+\tau a_{e k}+ \\
{\left[w_{k}\left(-s_{w 1}\right)-s_{w 2}\right] a_{k}=0}
\end{gathered}
$$

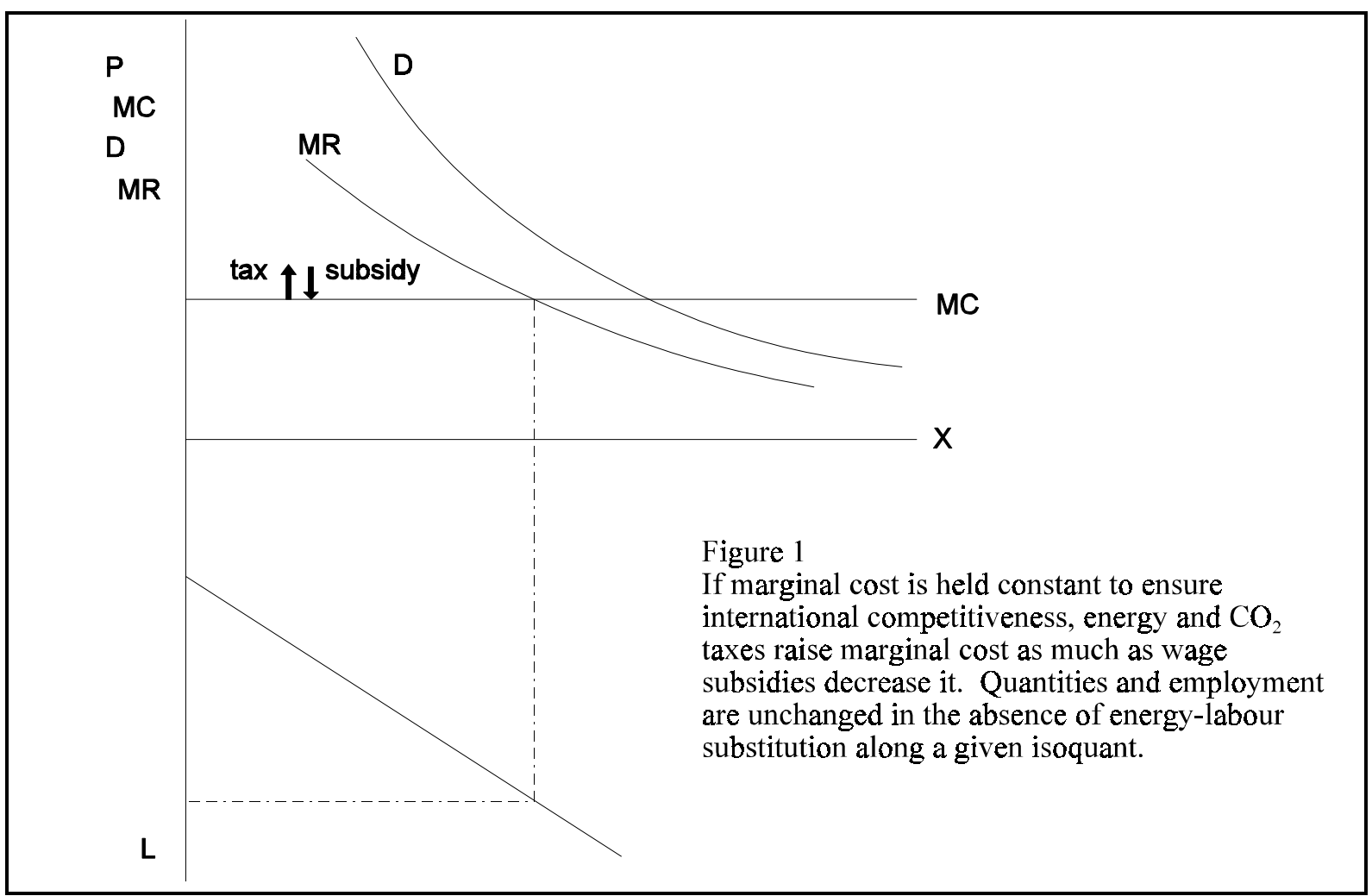

Marginal tax payments by the firm diminished by the reduction of the energy input coefficient must equal marginal subsidies received for wages if the competitive position has to be unchanged.

Multiplying by $x_{k}$ and summing over all firms $\mathrm{k}$ yields the condition for an unchanged competitive position for the economy that can be compared to the budget of the government:

$$
\begin{gathered}
\sum_{k} x_{k} d a_{e} p_{e}+t C O_{2} \sum_{k} a_{e k} x_{k} \\
+\tau \sum_{k} a_{e k} x_{k}+\sum_{k}\left[w_{k}\left(-s_{w 1}\right)-s_{w 2}\right] a_{k} x_{k}=0
\end{gathered}
$$

(26) says that to keep international competitiveness constant requires that the amount of carbon and energy taxes paid by the firms diminished by the value of reduced energy coefficients is equal to the amount of wage subsidies on variable labour cost. We look at the government budget to see what remains in the budget after these transactions are carried out. Rewriting the budget constraint of the government after replacement of $L_{k}$ by (3) yields: 


$$
\begin{gathered}
t \mathrm{CO}_{2} \sum_{k} x_{e k}+\tau \sum_{k} x_{e k}+t c_{e} C O_{2}+\tau c_{e} \\
s_{r} p_{r}\left(\sum_{k} x_{r k}+c_{r}\right)-\left[s_{w 1} w+s_{w 2}\right] \sum_{k}\left(f_{k}+a_{k} x_{k}\right)=
\end{gathered}
$$

Cancelling terms in (10') which add up to zero according to (26) yields

$$
\begin{gathered}
-\sum_{k} d a_{e} p_{e}+t C \mathrm{C}_{2} c_{e}+\tau c_{e} \\
-s_{r} p_{r}\left(\sum_{k} x_{r k}+c_{r}\right)-\sum_{k}\left[s_{w 1} w+s_{w 2}\right] f_{k}=0
\end{gathered}
$$

If the competitive position of firms has to be unaffected, then (more than $)^{14}$ the sum of carbon and energy tax revenues paid by households can be used for subsidies on energy-saving investments or to subsidize fixed labour costs. If households subsidizing firms' fixed labour costs is held to be undesirable from a political point of view there is a clear policy rule for $\mathrm{CO}_{2}$ and competition policy: the amount of carbon and energy tax revenues paid by firms can be used to subsidize variable labour costs, fixed costs going without subsidies, and the amount of carbon and energy tax revenues paid by households should be used to subsidize energy-saving measures of firms and households. An important analytical implication of this rule is that rebated revenues from carbon and energy taxes on firms serve the competitiveness goals by holding marginal costs constant and the environmental goal by reducing energy coefficients, whereas carbon and energy taxes of households serve the $\mathrm{CO}_{2}$ goal via subsidies for energy-saving investments. Alternatively, if marginal costs are allowed to decrease by the change in the energy coefficient when energy tax revenues paid by firms are exactly rebated to them, the first term in (10') drops out and the rules formulated above are slightly modified quantitatively but not principally. Taxes on carbon and energy use and subsidies for investment in energy-saving technologies help to decrease marginal cost and therefore increase competitiveness (see Figure 2). In sum, subsidies to energy-saving investments are not contradictory with respect to $\mathrm{CO}_{2}$ policy and competitiveness, whereas environmental taxes need compensation by wage subsidies to avoid negative effects on marginal costs or allow slightly positive ones.

A look at formulas (23) and (24) indicates that there are two complementary ways to have environmental policy without endangering international competitiveness on average. First, raise environmental taxes on firms and rebate the revenue as wage subsidies. Obviously, this policy would give an incentive to use energy-saving technologies according to equation (24) whereas marginal cost other than those from changing energy-coefficients could be kept constant on average. Without adding new constraints that are unmentioned so far, energy coefficients could be driven down very far in this way, keeping in mind that our static model ${ }^{15}$ brings this effect

${ }^{14}$ This is the case because of the first term in the equation, which is positive. To this extent $\mathrm{MC}$ is decreased and compensation on labour cost can be lower than the tax burdens.

${ }^{15}$ Newell et al. (1999) provide evidence that energy prices do not affect the rate of overall innovation but only the direction of innovation. With the rate of overall innovation unaffected by energy subsidies and taxes it seems unnecessary to model endogenous growth rates here and 
completely into the present. In reality this will be stretched out over many years because technical progress is a slow process. Second, tax households and subsidize energy-saving investments of households and firms. This also would bring down marginal costs by decreasing energy coefficients. Therefore it could be used in addition to the first approach.

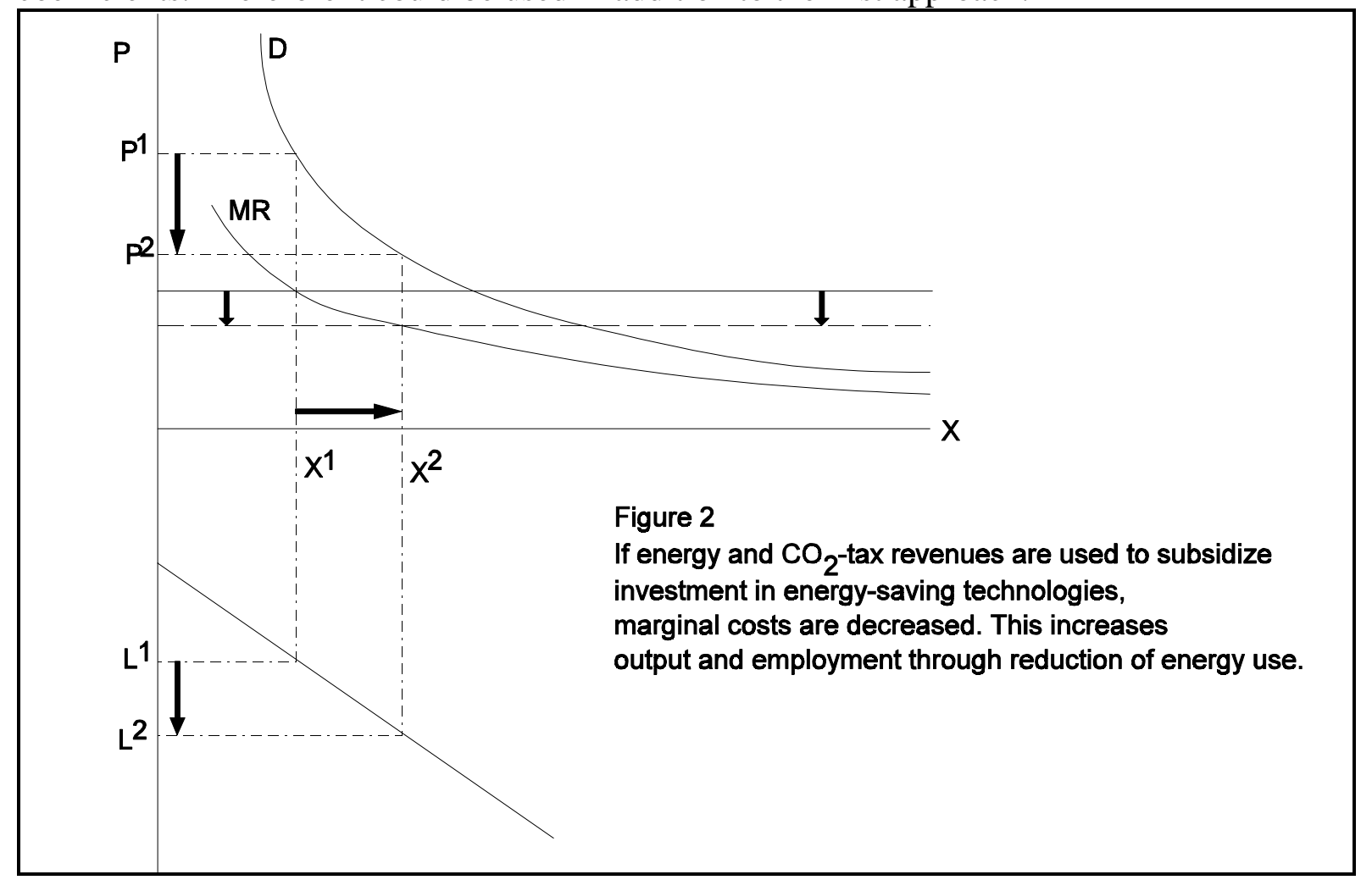

What are the limits to these policies? Some economists have argued that mixing environmental policy and wage policy is not in accordance with 'good economic order'. We do not pursue this line of research. Others would not like tax burdens to be increased; they would either suggest to reduce other taxes or to rebate the tax revenue, e.g., raised from households to households. This is a debate that touches the question of the design of optimal tax systems. Of course this can also not be done in this paper. But it seems to be in accordance with optimal taxation systems that we will use below the textbook structure of taxing the dirty or polluting activity and subsidize the good or less polluting alternative.

Politicians have detected a different problem related to equations (5) and (23). Firms would enjoy the same rates of subsidization of wages, but their energy coefficients are different, which means that they have different marginal cost increases from environmental taxes. By implication, firms with high energy input coefficients have increases in their marginal costs and therefore a loss in competitiveness. Although others must have a corresponding gain, politicians are afraid that the structural change involved might increase unemployment. There are two ways out of this problem. One of them is to politically muddle through, giving energy-intensive firms exemptions from environmental taxes, which of course strongly weakens the environmental effects of the policy and results in a strongly political determination of the allocation. The other way is to abandon environmental taxes on firms altogether, thus getting rid of the necessity to pay wage subsidies. Environmental policy then is made by taxing households, the beneficiaries of

a static model is complicated enough to derive the essential results. 
environmental policies, and giving subsidies to energy-saving investments to firms and households. We next explain that, with this policy, substitution is limited to the household part of the demand side whereas it leans on energy-saving investments of firms and households.

We will look in more detail at substitution on the production side of the economy because much of the literature has been based on substitution ideas. It is well known from the discussion on capital-energy substitution that the data used in empirical work are highly aggregated. Substitution is a composite effect of three sources: i) shifts in the structure of the activities from energy-intensive to less energy-intensive activities; ii) energy-saving technical progress; iii) substitution in the narrow sense of the word, i.e. along an isoquant at the product level. With highly aggregated data it is impossible to disentangle these three effects. Therefore, not only is capital-energy substitution an un-clarified issue (see J.L. Solow 1987) but so is the energy-labour substitution. A policy that holds the international competitiveness of sectors constant instead of building on sectoral shifts has to rely on the other sources. Moreover, even if energy-intensive sectors would not be protected against loss of competitiveness one should keep in mind that during the oil crises "the long-established trend of labour-intensive industries toward declining relative economic importance accelerated" (Marlay 1984, p.1279). Oil-price increases could have theoretically induced energy-labour substitution and capital-energy intensive sectors should have declined, but this didn't happen. Therefore it is much less likely to occur under a $\mathrm{CO}_{2}$ policy that increases energy prices much less than the oil crises did. Therefore, the first of the three sources of substitution is not available if sectors are protected against losing competitiveness via taxation, and substitution in the narrow sense, i.e. along an isoquant on the product level, is not a reliable way in itself. The only remaining basis for $\mathrm{CO}_{2}$ policy is energy-saving investments because "declining relative economic importance of industries intensive in their use of labour and energy, (is) suggesting a role for advanced technologies aimed at improving industrial productivity" and " to the extent that energy is an important factor in the costs of production, such technologies offer potentially significant competitive advantages" (Marlay, 1984, p.1282). Reduction of greenhouse gas emissions and unemployment therefore has to rely on investment in energy-saving technologies offirms and households, on substitution of households and all of the implied general equilibrium effects. Tax revenues should therefore be recycled in the form of subsidies for these investments when competitiveness is a political tabo and muddling through is not accepted as a systematic approach. These investments decrease marginal cost, increase production and labour demand in a clean way because energy coefficients are lower than without this policy (Figure 2).

The advantage of subsidies from the point of view of having three imperfections environmental externalities, unemployment and monopolistic competition - is that they are all affected positively by the subsidy. Suggestions for alternative instruments will also have to be evaluated with respect to these imperfections in an $\mathrm{x}$-best setting. It should be kept in mind that in this proposal subsidies to firms are financed by taxing the polluting households. The principle of causation is therefore applied to households and also internationally because each country pays for its own pollution reduction. Up to the exception made for producers in order to preserve competitiveness, this follows the textbook principle to tax the polluter and subsidize the clean alternative. This principle has been successfully applied to car pollution before (see Kemp 1995). Of course, adding an additional restriction such as 'international competitiveness' has some costs in making an instrument a bit more costly. However, in a world with many imperfections one has to make sure that improving on one imperfection is not made too much at the cost of worsening other imperfections. The international competitiveness constraint in this paper excludes cost 
increasing measures and therefore makes subsidies preferable to taxes. ${ }^{16}$

Moreover, subsidies in one country or region may induce another country to give subsidies to a close competitor to preserve his position in the competition. Thus subsidies provide an incentive to foreign countries to contribute to GHG policy by using international competition as an incentive mechanism for the participation in contributions to the solution of a global common problem.

\section{General equilibrium}

So far we have shown on the firm level that subsidies for energy-saving investments will reduce energy-input coefficients, monopolistic prices and increase labour demand. In this section we will show ${ }^{17}$ that these results also hold on the general equilibrium level, thus reducing unemployment and the monopolistic inefficiency when using subsidies for energy-saving investment. The essence of this line of thought is not that a substantial contribution to the unemployment problem can be expected. Rather it is that environmental policy can be initiated without aggravation of the unemployment problem. The results derived in this section are collected in Figure 3.

\section{INSERT FIGURE 3}

In the right part the Beveridge curve is drawn. To determine the unemployment rate and its change after the introduction of subsidies for energy-saving investments, we examine the two curves of the left part. The upward sloping BB curve is the bargaining curve as it is known from Pissaridis $(1990)^{18}$ : the higher the vacancy/unemployment ratio the larger the real wage from the bargaining process. In the appendix we show that this curve is also valid for this model.

The falling curve of the left quadrant is more complicated to get. To derive it we first show that the two first-order conditions and the zero-profit condition of the retrofitting sector, equations (23), (24) and (8) for $\mathrm{k}=\mathrm{r}$ with $\mathrm{t}=\tau=\mathrm{s}_{\mathrm{w} 1}=\mathrm{s}_{\mathrm{w} 2}=0$ are three equations that determine the price, the quantity and the retrofitting measures of that sector as functions of the vacancy/ unemployment ratio, the subsidy and the price of the other sectors, $\mathrm{p}_{\mathrm{k}}$. This is formally done in the appendix. In figure 4 we summarize the results, which can be explained as follows.

\section{INSERT FIGURE 4}

Figure 4a shows that the price for retrofitting measures is an increasing function of unit labour costs. The reason is that marginal and fixed labour costs both increase and therefore, under zeroprofit conditions, the price must go up. The increasing curve is shifted down by an increase of subsidies for retrofitting measures, because subsidies decrease the fixed costs for energy-saving technologies and increase the incentive to reduce energy-input coefficients, thus reducing marginal costs. Therefore prices decrease because fixed and marginal costs decrease.

Figure $4 \mathrm{~b}$ shows the profit-maximizing quantity of the retrofitting sector. As prices and

\footnotetext{
${ }^{16}$ Investment subsidies to preserve firms survival have also been proposed in a different setting by Carraro and Siniscalco (1992).

${ }^{17}$ For second-order conditions and technical details of this section see the appendix.

${ }^{18}$ See equation (A.1) of the appendix.
} 
marginal costs go up with unit labour costs, quantities decrease. Subsidies for energy-saving technologies are decreasing marginal costs and therefore increase the quantity, which is captured by an upward shift of the falling curve.

Figure $4 \mathrm{c}$ shows the quantity, $x_{r}$, of retrofitting measures that are applied in the retrofitting sector itself. It is a falling function of labour unit costs, because quantities are a falling function of labour unit costs and lower (higher) quantities provide a stronger (weaker) incentive to reduce energy-input coefficients.

All these three arguments captured on the vertical axes of figure 4 are functions of the vacancy/unemployment rate, the goods price $p_{k}$, the subsidy $s_{r}$, and the energy price $p_{e}$. What we use in the next step is the price function $\mathrm{p}_{\mathrm{r}}=\mathrm{p}_{\mathrm{r}}\left(\theta, \mathrm{s}_{\mathrm{r}}, \mathrm{p}_{\mathrm{k}}, \mathrm{p}_{\mathrm{e}}\right)$, which is part of the first-order condition of all other sectors $\mathrm{k} \neq \mathrm{r}$.

Next we consider the sectors $\mathrm{k} \neq \mathrm{r}$. The two first-order conditions and the zero-profit condition (23), (24) and (8) are three equations for $\mathrm{p}_{\mathrm{k}}, \mathrm{x}_{\mathrm{k}}, \mathrm{x}_{\mathrm{rk}}$, depending on the vacancy/unemployment ratio, $\theta$, subsidies, $\mathrm{s}_{\mathrm{r}}$, and energy prices $\mathrm{p}_{\mathrm{e}}$. When looking at the sectoral equilibrium, we take into account that a firm's change in $\mathrm{p}_{\mathrm{k}}$ also changes the valuation of hiring costs because all firms change the price. The results of the analysis is captured in Figure $5 . \mathrm{p}_{\mathrm{k}}$ turns out to be an increasing function of the vacancy/ unemployment ratio, $\theta$, which is shifted down by the subsidy.

\section{INSERT FIGURE 5}

Results for the quantities of output and retrofitting measures are ambiguous because of two differences with the analysis of the $r$ sector. First, a change in $p_{k}$ has an impact on hiring costs which interacts with all other effects in a 3x3 system. Second, a change in the vacancy/ unemployment ratio not only effects $\mathrm{p}_{\mathrm{k}}$ directly but also indirectly via its effect on $\mathrm{p}_{\mathrm{r}}$. Increased unit labour costs and increased prices $\mathrm{p}_{\mathrm{r}}$ increase marginal costs and therefore should be expected to decrease quantities of output and energy-saving investments. However, the price increase is an upward shift of the demand function which also shifts up the marginal revenue function and thereby induces higher quantities. The net effect could be clarified for the $r$ sector but not under the more involved circumstances of the analysis of the sectors $\mathrm{k} \neq \mathrm{r}$.

We use the wage as a numéraire and assume that all sectors have the same $g$ function in equation (5), the curve in figure 5. After turning this equation into a function into $1 / \mathrm{p}_{\mathrm{k}}$, is exactly the curve labelled FF that is falling in the upper quadrant of figure 3. Its intersection with the bargaining curve determines the vacancy unemployment ratio. Actually we now have a 7x7 system where the seven equations are the two first-order conditions of the $r$ sector and its zeroprofit conditions, and the respective conditions for the k sectors [(23), (24) and (8) for $\mathrm{k}=\mathrm{r}$ and $\mathrm{k} \neq \mathrm{r}$, counting them only once when talking of a $7 \mathrm{x} 7$ system) $]$ and the bargaining equation. These seven equations determine $\mathrm{p}_{\mathrm{k}}, \mathrm{x}_{\mathrm{k}}, \mathrm{x}_{\mathrm{rk}}$ (for $\mathrm{k}=\mathrm{r}$ and for $\mathrm{k} \neq \mathrm{r}$ ) and $\theta$. Next, the Beveridge curve is an additional equation from which we get the unemployment rate $\mathrm{u}$. An increase in the subsidy shifting up the FF curve in figure 3 corresponding to the downward shift in figure 5, increases the tightness ratio $\theta$, decreases unemployment. More employment then leads to more production according to equation (12). Whether or not pollution will decrease depends on the net effect of i) decreasing energy-input coefficients from higher energy-saving measures and ii) more output from increased employment. This ambiguity, of course, arises from trying to use one instrument in a way that three inefficiencies are improved in the first instance: environment, employment and the monopolistic inefficiency. However, there is a widespread view that employment effects of such policies are fairly small because the share of energy costs is very low. This gives the policy 
a chance to improve the environment. Whatever the result on the environment is, falling prices stemming from an increase in the subsidy, increases households material well-being. But, of course, it has to be financed leaving the net effect once again indeterminate. If foreign countries do not have a similar policy the substitution effect drives relative demand towards the domestic economy. This provides an incentive for foreign politicians to install a similar policy.

\section{Conclusion}

This paper argues that a 'double dividend' under a competitiveness constraint is more likely to be found in a policy that subsidizes energy-saving investments out of the revenues of a carbon/energy tax than in a policy in which the revenues are exclusively used to reduce labour costs. Besides reducing emissions directly, such a policy thus decreases marginal costs because firms reduce energy use. Reduced marginal costs increase output and therefore employment, leaving the net effect on emissions unclear unless output and employment effects are relatively weak.

Such policy is superior under the condition already agreed upon among EU politicians (that the international competitiveness of branches and firms should not suffer from $\mathrm{CO}_{2}$ abatement policy) so that no sectoral shift occurs via eco-taxes. Given the limited opportunities of substitution, at least in the short run, and on the product level, we doubt that the standard double-dividend story is convincing. In contrast, the energy-savings potentials are well known to be quite large (see Marlay 1984, Blok et al. 1990 and Velthuijsen 1993). Investment in energy-saving technologies is a road to GHG- emission reduction without endangering international competitiveness and employment of sectors.

The effects of the proposal are as follows:

i) Households pay energy and $\mathrm{CO}_{2}$ taxes which are used for subsidies on energy-saving investments of firms or households. Under the EC proposal the price level effect of taxes is roughly $10 \%$ for natural gas and heating gas oil. Substitution away from energy at the household level is likely to occur but will be modest. Demand for energy-saving products will increase. The effects are limited. The costs of the policy are spread over the entire population, the beneficiary of GHG emission reduction.

ii) Subsidies for energy-saving investments reduce the fixed costs of production. As a result marginal costs decrease, which leads to lower prices and higher employment, making fixed costs per unit of output lower. Consequently, greenhouse gas emissions will be reduced if employment effects are small enough, and employment will be marginally higher as well. Energy-intensive sectors have a chance to become 'clean' without being the source of a new employment problem. The decrease in marginal costs will lead to a decrease in prices. A reduction of marginal costs will have a favourable impact on the competitiveness of firms, thus reducing monopolistic inefficiency. Exports going from the EC to the rest of the world will benefit most because they don't suffer from a decrease in demand induced by the income effects of energy and $\mathrm{CO}_{2}$ taxes unless the rest of the world is induced to undertake the same policy. This is another potential advantage of this proposal, that the policy deadlock of "we do nothing if they do nothing" may be broken. Moreover, countries who have disadvantages from such international competition impacts may become more interested in finding a solution for the greenhouse effect in an internationally coordinated way. This may speed up the process started in Kyoto. The US government has invested already $\$ 6.3$ billion over five years to encourage energy efficiency and the use of cleaner energy sources. This amount is low compared to the OECD estimate of $\$ 750$ 
billion yearly carbon tax revenues ${ }^{19}$ and it seems to be available only for technology adoption. The corresponding number for the Netherlands is 1 billion guilders per year. If this type of subsidy is an essential part of a political equilibrium it should be possible to shift more money - also for $R \& D$ of all useful sorts ${ }^{20}$ - into this strategy. This could be considered a great improvement, if one wants to buy more insurance again the GHG emissions risks than one has now. Moreover, according to the concept explained in this paper they must be strong enough to generate an incentive for countries to use positive incentives as well.

iii) If politicians believe in energy-labour substitution at the product level or allow for sectoral shifts, firms can be taxed for energy use and $\mathrm{CO}_{2}$ pollution as well and the revenues could be used for employment subsidies. This by itself could keep marginal cost on the firm level constant in the short run.

In sum, subsidies on investment in energy-saving technologies paid out of carbon and energy taxes of households are a way to stimulate competitiveness - reducing monopolistic inefficiencies - and employment and achieve GHG emission reductions provided output and employment effects are small, if policy makers want to safeguard competitiveness of energyintensive sectors. Moreover, subsidies may induce other countries to undertake a similar policy and the process started in Rio and Kyoto may be speeded up.

\section{References}

Blok, K., E. Worrel, R.A.W. Albers, R.F.A. Cuelenaere (1990), Data on energy conservation techniques for the Netherlands, Vakgroep Natuurwetenschap en Samenleving, Rijksuniversiteit Utrecht.

Brenton, P., 1994, Estimation of Cross-Country Consumption Patterns: Implications for Carbon Abatement Policies, The University of Birmingham, Department of Economics Discussion Paper No. 94-12.

Carraro, C. and D. Siniscalco, 1992, Environmental Innovation Policy and International Competition, Environmental and Resource Economics 2: 183-200.

Cooper, Richard N., 1998, Toward a Real Global Warming Treaty, Foreign Affairs, Vol. 77 No.2, March/April, 66-79.

Deaton, A.S., 1975, The measurement of income and price elasticities, European Economic Review 6, 261-273.

Denis, C. and G.J. Koopman, 1995, Differential Treatment of Sectors and energy Products in the Design of a $\mathrm{CO}_{2}$ /Energy Tax: Consequences for Employment, Economic Welfare and $\mathrm{CO}_{2}$ Emissions, NOTA DI LAVORO 32.95, Economics energy environment, Fondazione Eni Enrico

\footnotetext{
${ }^{19}$ See Cooper 1998 p.77.
}

${ }^{20}$ See Jacoby, Prinn and Schalensee (1998) pp.61-66 for the need of R\&D finances. Public $R \& D$ budgets allocate more than five times as much money to nuclear energy ( $\$ 5$ billion) than into research into renewables (\$878 million). (The Economist June 14, 1997) 
Mattei, Milano, Italy.

Dixit, A. and J.E. Stiglitz, 1977, Monopolistic Competition and Optimum Product Diversity, American Economic Review 67, 297-308.

Eizenstat, S., 1998, Stick with Kyoto, Foreign Affairs, Vol. 77 No.3, May/June, 119-121.

Europaeische Gemeinschaften, 1994, Energiepreise 1973-1993, Luxembourg.

Hall, R.E, 1988, The Relation between Price and Marginal Cost in U.S. Industry, Journal of Political Economy, Vol. 96, no.5, 921-47.

------, 1990, Invariance Properties of Solow's Productivity Residual, in: Growth/ Productivity/ Unemployment, edited by P.A. Diamond, MIT Press, Cambridge, Massachusetts, London, England, 71-112.

Helpman, E. and P.R. Krugman, 1985, Market Structure and Foreign Trade, Harvester Wheatsheaf, Brighton.

HERMES 1993, Harmonized Econometric Research for Modelling Economic Systems, edited by: Commission on the European Communities, North-Holland, Amsterdam.

IPCC Draft Guidelines for National Greenhouse Gas Inventories, Greenhouse Gas Inventory Reference Manual, First Draft, Volume 3.

Jacoby, H.D., R.G. Prinn and R.Schmalensee, 1998, Kyoto's Unfinished Business, Foreign Affairs, Vol.77 No.4, July/August, 54-66.

Kemp, R., 1995, Environmental Policy and Technical Change, A Comparison of the Technological Impact of Policy Instruments, Universitaire Pers Maastricht.

Kouris, G., 1983, Energy Demand Elasticities in Industrialized Countries: A Survey, The Energy Journal, Vol. 4, No.3, 73-94.

Li, Hongyi and G.S. Maddala, 1999, Bootstrap Variance Estimation of Nonlinear Functions of Parameters: An Application to Long-Run Elasticities of Energy Demand, The review of economics and statistics, vol 81, (4), 728-733.

Maddala, G.S., R.P. Trost, H.Li, F.Joutz, Estimation of Short-Run and Long-Run Elasticities of Energy Demand From Panel Data Using Shrinkage Estimators, Journal of Business \& Economic Statistics, January 1997, Vol.15, No.1, 90-100.

Marlay, R.C., 1984, Trends in Industrial Use of Energy, Science Vol. 226, December, 1277-1283.

Michaelis, P., 1999, Sustainable Greenhouse Policies: The Role of Non- $\mathrm{CO}_{2}$ Gases, Structural-Change-and-Economic-Dynamics, 10(2), June, pages 239-60. 
Mittelstädt, A., 1983, Use of Demand Elasticities in Estimating Energy Demand, OECD, 46.p.

Morrison, C.J., 1989 , Unravelling the productivity growth slowdown in the U.S., Canada, and Japan, NBER Working Paper 2993.

-------, 1990, Market Power, Economic Profitability and Productivity Growth Measurement: An Integrated Structural Approached. NBER Working Paper 3355, May.

, 1992, Unravelling the Productivity Growth Slowdown in the United States, Canada and Japan: The Effects of Subequilibrium, Scale Economies and Markups, The Review of Economics and Statistics, Vol.LXXIV, August, Number 3, 381-93.

Newell, Richard G., A.B. Jaffe, R.N. Stavins, 1999, The Induced Innovation Hypothesis and Energy-Saving Technological Change, The quarterly journal of economics vol 114 (3), 941-976.

Pirttilä, Jukka, 1999, Earmarking of Environmental Taxes and Pareto-Efficient Taxation, Finanzarchiv, vol 56 (2), 202-217.

Pissaridis, C., 1990, Equilibrium Unemployment Theory, Basil Blackwell.

SEO Onderzoek, 1992, Prijselasticiteit van het huishoudelijk energieverbruik, Amsterdam.

Soete, L. and T. Ziesemer, 1997, Gains from Trade and Environmental Policy under Imperfect Competition and Pollution from Transport, in: H.D. Feser and M. von Hauff (eds.), Neuere Entwicklungen in der Umweltökonomie und -politik, transfer verlag, Regensburg. 249-267.

Solow, J.L., 1987, The Capital-Energy Complementarity Debate Revisited, American Economic Review, September, 605-614.

Velthuijsen, J.W., 1993, Incentives for Investment in Energy Efficiency: An Econometric Evaluation and Policy Implications, Environmental and Resource Economics 3: 153-169.

Vermeend, W. and J. van der Vaart, 1997, Greening Taxes: The Dutch Model, Paper for the EAERE, Tilburg. 


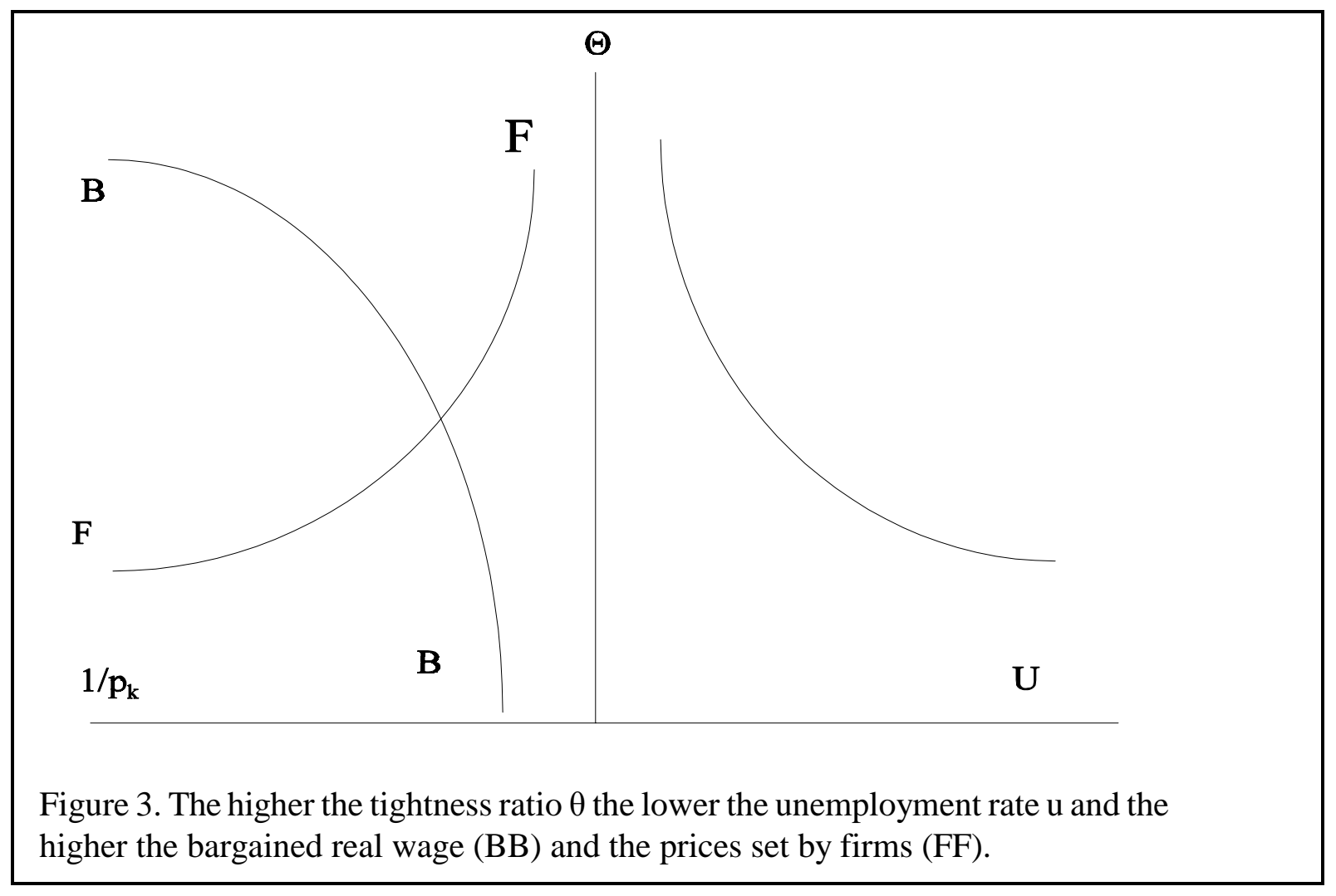




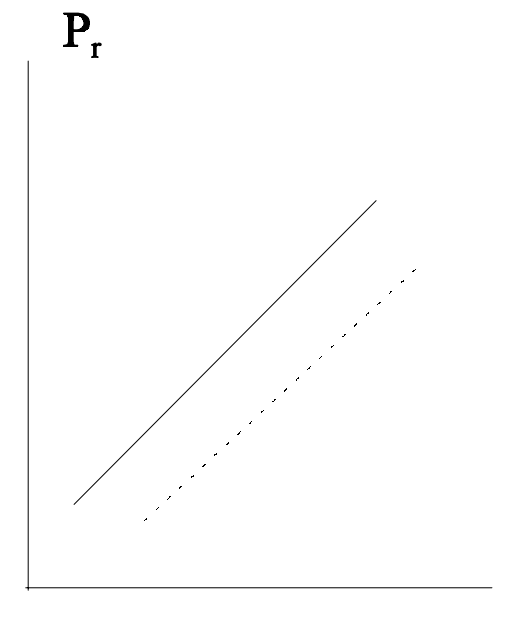

$\mathrm{W}+\mathrm{h}$

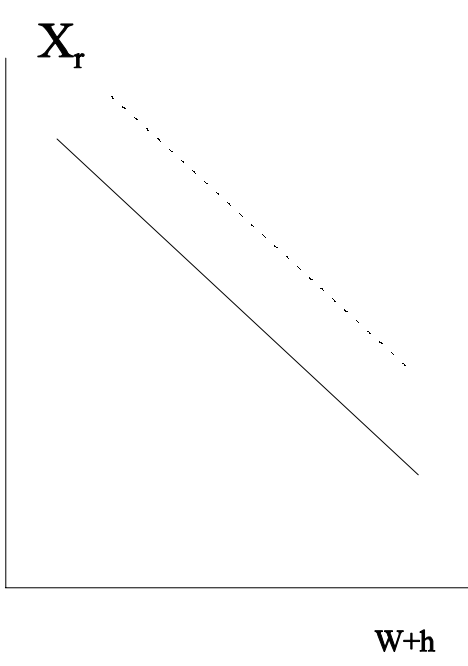

(b)

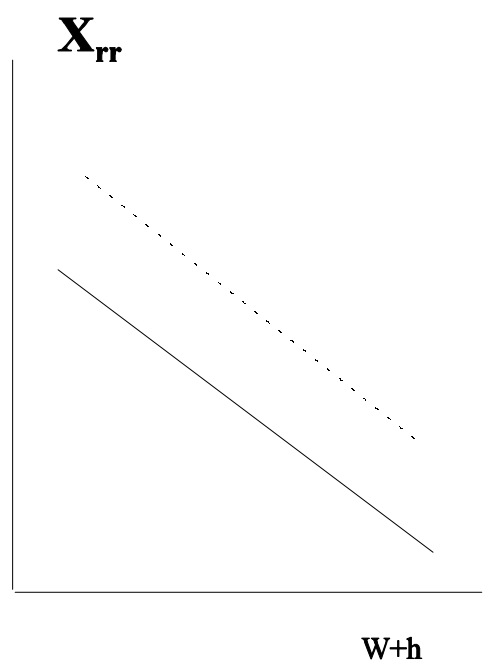

(c)

Figure 4. An increase in labour costs (subsidies) (a) increases (decreases) prices, (b) decreases (increases) the output and (c) decreases (increases ) energy-saving investment of the retrofitting sector.

$\Theta$

Figure 5. An increase in the tightness ratio (subsidies) increases (decreases) firm's prices. 


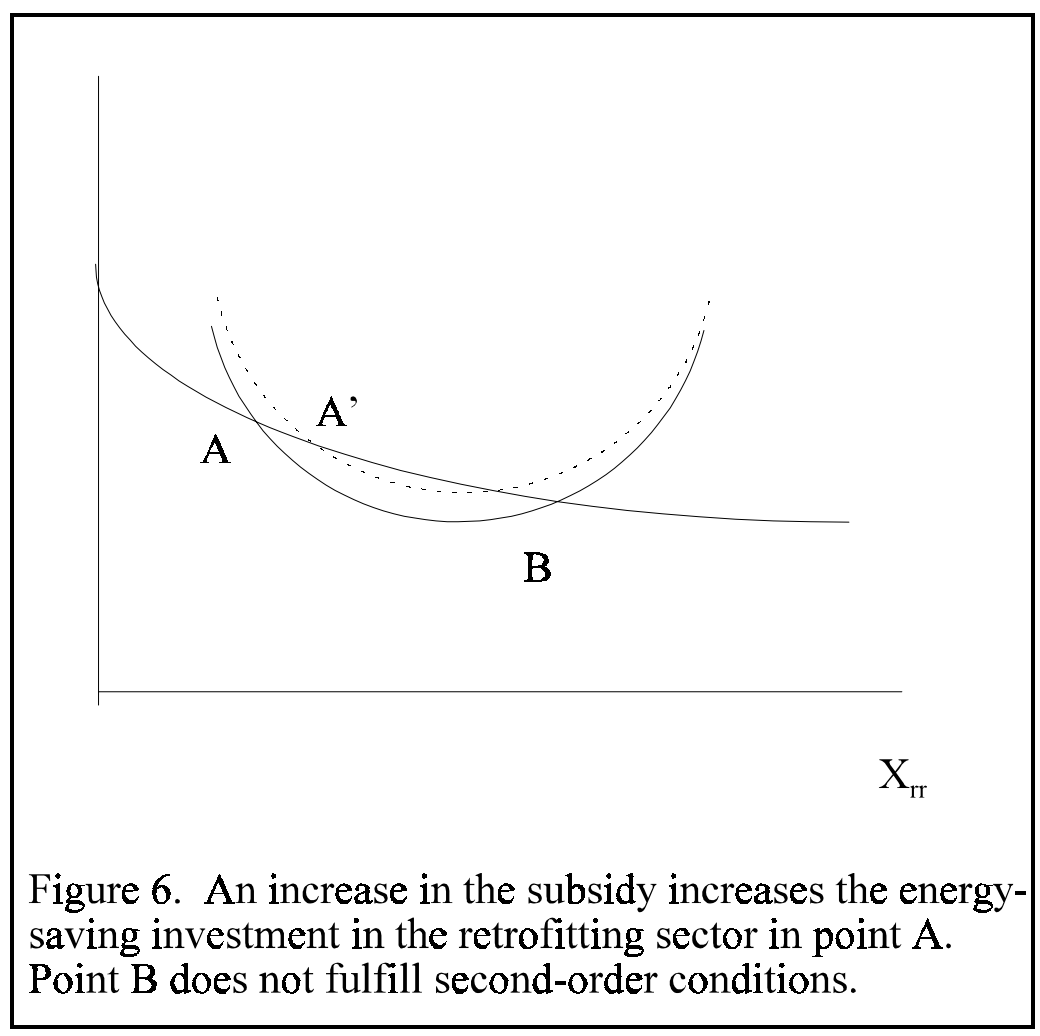




\section{Appendix (not for publication)}

\section{Basics of search unemployment theory}

From the Pissaridis (1990, chap.1) model we use the matching function $m L=m(u L, v L)$, where $L$ is the number of workers, $u$ is the unemployment rate, $v$ is the rate of vacancies and $m L$ is the number of matches produced by this function. The function is assumed to be increasing in both arguments, concave and linearly homogenous. Defining $\theta=v / u$, division of the matching function by $v L$ yields $q(\theta)=m(u / v, 1)$ as the probability of a firm to find a worker for a vacancy and $\theta q(\theta)$ $=m / u=m(1, v / u)$ as the probability of an unemployed worker to find a job. A shock is a percentage rate $\mathrm{b}$ at which $(1-u) L$ employed workers loose their job by assumption in every period. Therefore $b(1-u) L$ workers go from a job into unemployment every period. On the other hand $\theta q(\theta) u L$ unemployed workers expect to find a job each period. Labour market equilibrium is defined as a situation where the numbers of workers going into and out of unemployment are equal and expectations turn out to be true, i.e. $b(1-u) L=\theta q(\theta) u L$. Solving this equation for $u$ yields the Beveridge or UV curve (lower indices referring to variables indicate partial derivatives):

$u=\frac{b}{b+\theta q(\theta)}, u_{b}>0, u_{\theta}<0$

The present-discounted value of the expected income stream of an unemployed and an employed worker, $U$ and $E$ respectively, are: $U=[Z+\theta q(\theta)(E-U)] / \rho$ and $E=[W+b(U-E)] / \rho{ }^{21} Z$ denotes the unemployment benefit and $E-U$ is the income difference an unemployed worker can gain by finding a job with probability $\theta q(\theta)$. W is the wage and $U-E$ is the corresponding loss of a worker from losing his job with probability $b$. Solving the second of the two equations for $E$ yields $E=$ $(W+b U) /(\rho+b)$. All these expressions here are defined in nominal terms. These two equations can be solved for E and U explicitly:

$$
U=\frac{(\rho+b) Z+\theta q(\theta) W}{\rho+b+\theta q(\theta)} / \rho \quad E=\frac{b Z+[\rho+\theta q(\theta)] W}{\rho+b+\theta q(\theta)} / \rho
$$

The present-discounted value of a vacancy is $V=\left[-\gamma p_{k}+q(\theta)(J-V)\right] / \rho$. It consists of the nominal hiring costs $\gamma p_{k}$ and the net return of transferring the vacancy $V$ into a job with value $J$ expected with probability $q(\theta) . \rho$ is the discount rate. As the value of the vacancy is zero in equilibrium, we get $J=\gamma p_{k} / q(\theta)$ : the value of a job is equal to the vacant job costs $\gamma p_{k}$ multiplied by the expected duration of the vacancy $l / q(\theta)$. When considering the firms' hiring costs it has to be taken into account that the occupied job may be separated from the worker again with probability $b$. The current value of the expected value of a job therefore is $(\rho+b) J=(\rho+b) \gamma p_{k} / q(\theta)$. These are labour costs that are added to the nominal wage received by the worker. Labour costs then equal $W+(\rho+b) p_{k} \gamma / q(\theta)$. Dividing the expression by the price of goods $\mathrm{k}$ yields the usual expression in real terms.

${ }^{21}$ If our model were of the endogenous growth type the division would not be by $\rho$ but rather by $\rho-g$, where $g$ is the steady state growth rate. A change in the growth rate would affect employment via the so-called capitalization effect. However, as Newell et al. (1999) provide evidence that energy prices do not affect this growth rate nothing would be changed here in a model that has a specification that leaves $g$ unaffected by energy prices and policies. Therefore we limit our model to a static one. 
Pissaridis (1990) links the above to the neo-classical production function. Here we link it to the model of this paper. If the temporary utility functions defined in the text are discounted

and integrated we may get the inter-temporal utility function

$$
\int_{t=0}^{\infty} e^{-\rho t} y(t) d t
$$

It is well known from endogenous growth theory or the theory of optimal growth that, in the absence of productivity growth, the value of consumption will be stationary and the interest rate will equal the discount rate $\rho$. This is the shortest way to determine the interest rate.

Workers and firms are assumed to determine the wage $\mathrm{W}_{\mathrm{j}}$ by bargaining over rents. The rents are $E_{j}-U$ and $J_{j}-V$, the difference between income from being employed and being unemployed, and the difference in value for a job and a vacancy. Hiring costs are obtained from the zero-profit condition of a bargaining firm $\mathrm{j}$ as

$J_{j}=\gamma p_{k} / q\left([)=\left\{\left[p_{k} x_{k}-\left(1-s_{r}\right) p_{r} x_{r k}-p_{e} g\left(x_{r k}\right) x_{k}\right] /\left(f+a x_{k}\right)-W_{j}\right\} /(\rho+b)\right.$

Bargaining occurs through maximising the function $\left(E_{j}-U\right)^{\beta}\left(J_{j}-V\right)^{l-\beta}$ with respect to the wage $\mathrm{W}_{\mathrm{j}}$, with $\beta$ as the bargaining power of workers and $1-\beta$ that of firms, $V=0, E_{j}=\left[W_{j}+b U\right] /(\rho+b), U$ according to the explicit solution given above. The result is that workers achieve a share $\beta$ of the sum of the rents: $E_{j}-U=\beta\left(E_{j}-U+J_{j}-V\right)$. Insertion of the above expressions for all the terms and solving for the wage yields ${ }^{22}$

$W_{j}=(1-\beta) \rho U+\beta\left[p_{k} x_{k}-\left(1-s_{r}\right) p_{r} x_{r k}-p_{e} g\left(x_{r k}\right) x_{k}\right] /\left(f+a x_{k}\right) \quad$ with $\rho U=Z+p_{k} \theta \beta \gamma /(1-\beta)$,

where the last expression is obtained from insertion of $E_{j}-U=\beta\left(E_{j}-U+J_{j}-V\right)$ and $J_{j}=\gamma p_{k} /$ $q(\theta)$ into $\rho U=[Z+\theta q(\theta)(E-U)]$. Insertion of $\rho U$ into the wage equation yields ${ }^{23}$

$W_{j}=(1-\beta) Z+p_{k} \theta \beta \gamma+\beta\left[p_{k} x_{k}-\left(1-s_{r}\right) p_{r} x_{r k}-p_{e} g\left(x_{r k}\right) x_{k}\right] /\left(f+a x_{k}\right)$

It follows from the zero-profit condition that the fraction in the last term after the $\beta$ equals wage plus hirings costs. Therefore the equation can be re-written as

$W_{j}=(1-\beta) Z+p_{k} \theta \beta \gamma+\beta\left[W+(\rho+b) \gamma p_{k} / q(\theta)\right]$

In equilibrium, bargained and market wages must be the same. Solving for $W$ yields

$W=Z+\beta \gamma p_{k}\{[\theta q(\theta)+(\rho+b)] / q(\theta)\} /(1-\beta)$

Dividing by $\mathrm{p}_{\mathrm{k}}$ yields the bargaining curve drawn in figure 3:

$W / p_{k}=z+\beta \gamma\{[\theta q(\theta)+(\rho+b)] / q(\theta)\} /(1-\beta)$, with $z=Z / p_{k}$.

If the exogenous unemployment benefit $\mathrm{z}$ is given in real terms then this is an equation in two

\footnotetext{
${ }^{22}$ This equation corresponds to equation 1.18 in Pissaridis 1990.

${ }^{23}$ This equation corresponds to equation 1.19 in Pissaridis 1990.
} 
variables: the real wage and the vacancy/unemployment ratio.

The corresponding curve for the r-sector would be divided by $\mathrm{p}_{\mathrm{r}}$ instead of $\mathrm{p}_{\mathrm{k}}$. That means that in figure 3 the curves would be shifted by a $\mathrm{p}_{\mathrm{k}} / \mathrm{p}_{\mathrm{r}}$. It can be shown that this ratio is larger than one. This means that the two intersecting curves would both be shifted to the left and intersect at the same vacancy/ unemployment ratio. The reason why $\mathrm{p}_{\mathrm{k}}>\mathrm{p}_{\mathrm{r}}$ is as follows (proof by contradiction): In each sector we have $\mathrm{p}_{\mathrm{i}}=\mathrm{MC}_{\mathrm{i}} / \alpha$. this means that equal $\mathrm{MC}$ in both sectors would imply equal prices irrespective of the position of the demand curve; a demand curve that is at the upper right of the other demand curve leads to higher quantities but not higher prices. The retrofitting sector has higher demand because at hypothetically identical prices it has the same demand from households and exports, but a demand from firms as well. Higher quantities, however, imply higher energy demand and a stronger incentive to buy energy saving investment goods, which in turn decrease energy-coefficients. therefore the retrofitting sector has lower marginal costs and lower prices than the other sectors. This is an interesting result independent of the context of the paper: higher demand may lead to lower prices when technology choice is involved.

\section{Second-order conditions}

Second-order conditions require that the second derivatives with respect to the same variables are negative. Moreover, the determinant of the Hessian of the profit function must be positive:

$$
\left|\begin{array}{l}
p_{k}{ }^{\prime},-p_{e} g^{\prime} \\
-p_{e} g^{\prime},-p_{e} g^{\prime \prime} x_{k}
\end{array}\right|>0
$$

Calculation of the determinant, using $p^{\prime} x=p(\alpha-1)$, yields:

$$
p_{k}(1-\alpha) p_{e} g^{\prime \prime}-\left(-p_{e} g^{\prime}\right)^{2}=-p_{e} g^{\prime}\left[p_{k}(1-\alpha) g^{\prime \prime} /\left(-g^{\prime}\right)+p_{e} g^{\prime}\right]>0
$$

\section{Partial equilibrium of the sector for energy-saving technologies}

Solving the zero-profit condition of sector $r$ for its price $p_{r}$ - after setting all policy instruments except for the subsidy equal to zero -, and replacing, first, $x_{r}$ by $x_{r}=\left(1-s_{r}\right) p_{r} /\left[-g^{\prime}\left(x_{r r}\right) p_{e}\right]$ from the first-order condition concerning $x_{r r}$, and second $p_{r}$ by its value from the first-order condition with respect to $x_{r}$, yields after some manipulation (with h as nominal hiring costs as defined in the text):

$$
\frac{1-\alpha}{\alpha^{2}}\left[p_{e} g_{r}\left(x_{r r}\right)+(w+h) a\right]^{2}=\left[\frac{(w+h) f}{1-s_{r}}+x_{r r} \frac{p_{e} g_{r}+(w+h) a}{\alpha}\right]\left[-g^{\prime}\left(x_{r r}\right) p_{e}\right]
$$

The term in square brackets on the left-hand side is marginal costs. The function on the left hand side is a falling function of $x_{r r}$ with vertical intercept $\left[p_{e} \underline{a}_{e}+(w+h) a\right]^{2} /\left[\alpha^{2} /(1-\alpha)\right]$ drawn in figure 6 . The right-hand side goes towards infinity for $x_{r r} \rightarrow 0$. On the other hand, if $x_{r r} \rightarrow \infty,-g^{\prime} x_{r r} \rightarrow \infty$. As the right hand side comes from and goes to infinity it must have at least one minimum. Around each minimum the curve has a $\mathrm{u}$-shaped form. By implication, there is either no intersection or 
there is an even number of intersections, half of which have a RHS curve falling at the intersection point and the other half have a positive slope. The slopes of the curves can be calculated as follows:

$$
\begin{gathered}
\frac{\partial L H S}{\partial x_{r r}}=\frac{2(1-\alpha)}{\alpha^{2}}\left[p_{e} g_{r}+(w+h) a\right] p_{e} g^{\prime}<0 \\
\frac{\partial R H S}{\partial x_{r r}}=-p_{e} g^{\prime \prime}\left[\frac{(w+h) f}{1-s_{r}}+x_{r r} \frac{p_{e} g_{r}+(w+h) a}{\alpha}\right]-p_{e} g^{\prime} \frac{p_{e} g_{r}+(w+h) a}{\alpha}-p_{e} g^{\prime} x_{r r} p_{e} g^{\prime} / \alpha
\end{gathered}
$$

In the last derivative the first and the third of the three terms are negative whereas the second is positive. Using the fact that the fixed cost term in square brackets can be rewritten as $p_{r}(1-\alpha) x_{r}$ under a zero-profit constraint, and the fraction in the second term equals $p_{r}$ we show that the second term is outweighed by the first term:

$$
\begin{aligned}
& -p_{e} g \text { ' } F C /\left(1-s_{r}\right)-p_{e} g \text { ' }\left[p_{e} g_{r}+(w+h) a\right] / \alpha=-p_{e} g \text { ' ' } p_{r}(1-\alpha) x_{r} /\left(1-s_{r}\right)-p_{e} g \text { ' } p_{r}= \\
& -x_{r} /\left(1-s_{r}\right)\left[p_{e} g \text { ' } p_{r}(1-\alpha)+p_{e} g^{\prime} p_{r}\left(1-s_{r}\right) / x_{r}\right]=-x_{r} /\left(1-s_{r}\right)\left[p_{e} g{ }^{\prime} p_{r}(1-\alpha)-\left(p_{e} g\right)^{2}\right]<0
\end{aligned}
$$

In the last step the second-order condition for $x_{r r}$ has been used. The term in square brackets has the sign of the second-order conditions of profit maximization and therefore the whole term is negative. By implication the relevant intersection points are those where the RHS curve is falling. In figure 6, where the special case with two intersection points is drawn this is the intersection point which is more on the left.

A subsidy for energy saving technologies shifts up the RHS curve and therefore increases $x_{r r}$ as drawn in figure 6 . This decreases energy-input coefficients in the first-order condition for the quantity, $x_{r}$, and therefore, given labour costs, it decreases $p_{r}: d p_{r} / d x_{r r}=p_{e} g^{\prime} / \alpha<0$. The firstorder condition for $x_{r r}$, solved for $x_{r}=\left(1-s_{r}\right) p_{r}\left(x_{r r}\right) /\left[-g^{\prime}\left(x_{r r}\right) p_{e}\right]$ can then be shown to prove that the quantity of the energy-saving technologies is increased. $d x_{t} / d x_{r r}$ turns out to be positive if the second-order conditions are fulfilled and $\alpha \geq 1 / 2$ (sufficient), which is assumed to be the case henceforth.

Next we consider the impact of an increase in wage costs $w+h$. We find

$\partial L H S / \partial(w+h)=(1-\alpha) 2 M C a / \alpha^{2}>0$ and $\partial L H S / \partial(w+h)[(w+h) / L H S=2(w+h) a / M C$, which is larger than unity if marginal labour costs $(w+h) a$ is the larger part of marginal costs, i.e., larger than marginal energy costs;

$\partial R H S / \partial(w+h)=-p_{e} g^{\prime}\left[f /\left(1-s_{r}\right)-x_{r r} a / \alpha\right]$ and $\left.\partial R H S / \partial(w+h)[w+h) / R H S\right]<1$ as RHS is linear in $w+h$ and $p_{e} g_{r}$ drops out in the derivation. By implication LHS is increased more strongly by an increase of unit wage costs, $d(w+h)$, than RHS is. Consequently $x_{r r}$ falls at the relevant equilibrium when unit wage costs increase. By implication energy coefficients increase and so do marginal costs as both its components go up and therefore prices are increased as well. To get the impact on the profit-maximizing quantity we can again use $x_{r}=\left(1-s_{r}\right) p_{r}\left(x_{r r}\right) /\left[-g^{\prime}\left(x_{r r}\right) p_{e}\right]$ which yields $d x_{r} / d x_{r r}>0$ if the second-order conditions are fulfilled and $\alpha \geq 1 / 2$ (sufficient). As $x_{r r}$ falls $x_{r}$ also falls when unit wage costs are increased. All of these results are summarized in Figure 4ac. 
What we need in the analysis of the other sectors is that $\mathrm{p}_{\mathrm{r}}$ is a function of wage costs, subsidies and energy prices, with nominal unit hiring cost being a function of the vacancy/ unemployment ratio and goods prices $p_{k}: p_{r}=p_{r}\left[w+h\left(\theta, p_{k}\right), s_{r ;} p_{e}\right]$. To get the falling curve in the upper quadrant of figure 3 we need a relation between $p_{k}$ and the vacancy/unemployment ratio and we need to know how it shifts with changes in the subsidies. The analysis runs as follows.

\section{Equilibrium of the other sectors}

The two first-order conditions and the zero-profit condition, (23), (24), (8) for $k \neq r$, using the wage as numéraire, forms a system of three equations for the price, $p_{k}$, the quantity, $x_{k}$, and the investment in energy-savings measures, $x_{r k}$, all as functions of the vacancy/unemployment ratio, $\theta$, the subsidy $s_{r}$, and energy prices $p_{e}$. We first show for the partial equilibrium (where $p_{r}$ and $p_{k}$ as the valuation of hiring costs is perceived to be given and constant) that subsidies increase the investment in energy-saving measures for given $\theta$. Solving the zero-profit condition for $p_{k}$, replacing $x_{k}$ by its value from the first-order condition for $x_{r k}, x_{k}=\left(1-s_{r}\right) p_{r} /\left[-g^{\prime}\left(x_{r k}\right) p_{e}\right]$, and replacing marginal cost terms by $p_{k} \alpha$, and eliminating $p_{k}$ by using the first-order condition for output, we get an equation as in figure 6 for the $r$ sector. Again the relevant equilibrium is found by using second-order conditions. Again the subsidy shifts up the u-shaped function and increases $x_{r k}$.

Totally differentiating the three equations, the first-order conditions for $x_{k}, x_{r k}$ and $p_{k}$, totally with respect to these three variables and with respect to $\theta$, where the differentiation includes a change in the valuation of the hiring costs with respect to $p_{k}$, we get the following system to which the Cramer rule can be applied after division by $d \theta$ :

$$
\left[\begin{array}{ccc}
p_{k}{ }^{\prime} \alpha & p_{e} g^{\prime} & \alpha-(\rho+b) \gamma / q \\
-p_{e} g^{\prime} & -p_{e} g^{\prime \prime} & \left(s_{r}-1\right) \frac{\partial p_{r}}{\partial p_{k}} \\
0 & 0 & x_{k}-(\rho+b) \gamma / q
\end{array}\right]\left[\begin{array}{c}
d x_{k} \\
d x_{r k} \\
d p_{k}
\end{array}\right]=\left[\begin{array}{c}
a \\
-\left(s_{r}-1\right) \frac{\partial p_{r}}{\partial(w+h)} \frac{\partial(w+h)}{\partial \theta} \\
{\left[\begin{array}{c}
\partial p_{r} \\
-\left(s_{r}-1\right) \frac{\partial(w+h)}{\partial(w k}+f+a x_{k}
\end{array}\right] \frac{\partial(w+h)}{\partial \theta}}
\end{array}\right] d \theta
$$

As the third element in the third row of the $3 \times 3$ matrix is positive, the determinant of this matrix is positive whenever second-order conditions are fulfilled. Applying Cramer's rule to get $\partial p_{k} / \partial \theta$, brings the third element of the vector of the right hand side into the position of the third row and column. As this term is also positive, the matrix obtained in this way, which can be called $\mathrm{A}_{3}$, also has a positive determinant. Cramer's rule then says that $\partial p_{k} / \partial \theta=/ A_{3} / / \mid A />0$ as both determinants are positive. Vertical lines indicate that a determinant is considered. If the right hand side of the system would be the differentiation of the system with respect to subsidies, we would have the positive effect of subsidies on profits in the third position, with changing its sign when bringing it to the right hand side. Applying Cramer's rule again would bring this element into the position $(3,3)$ and its sign yields the result $\partial p_{k} / \partial s_{r}=/ A_{3} / / / A /<0$. Similarly, one can show $\partial x_{k} / \partial s_{r}$, whatever the sign of the effect $\partial x_{k} / \partial \theta$ is. 